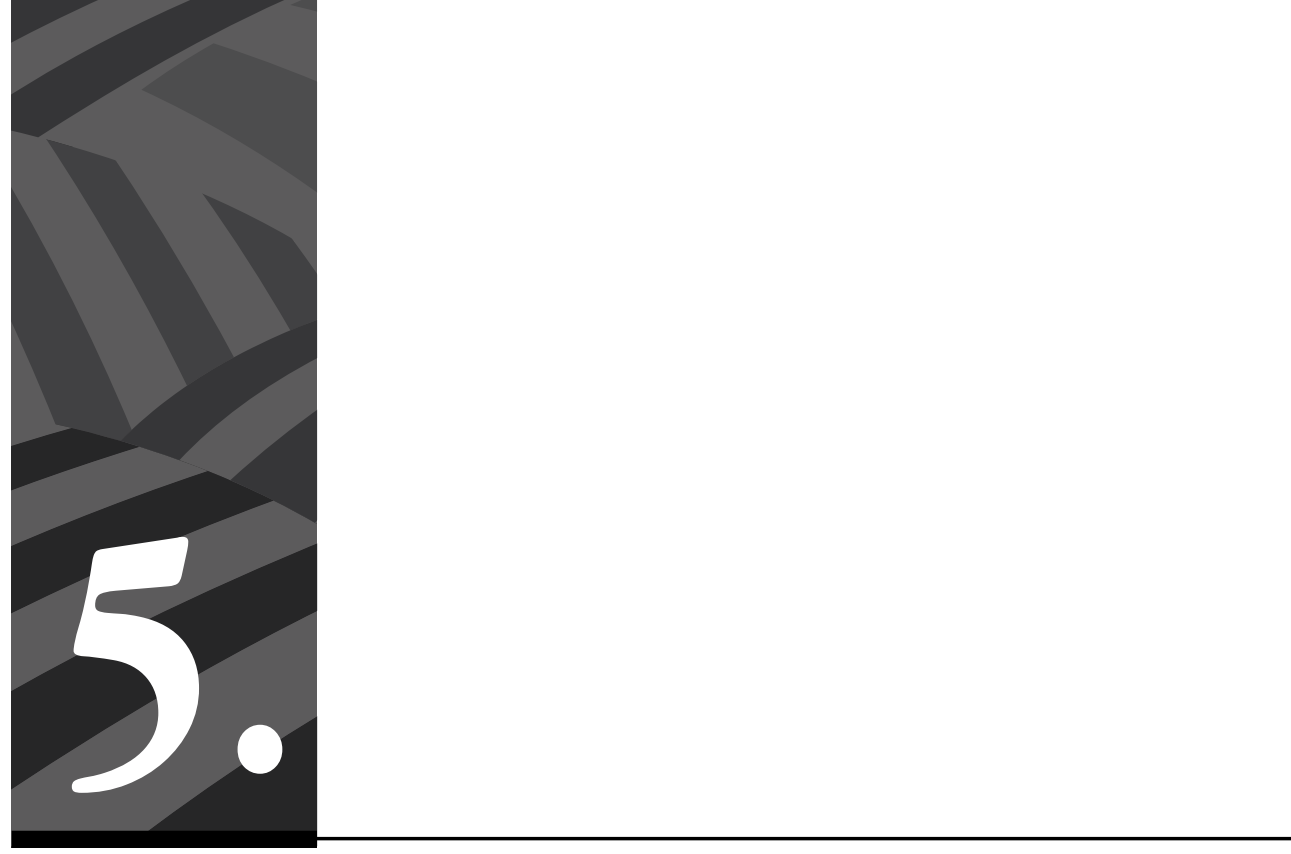

La paz imperfecta: una mirada a los puntos de tierras, participación política y solución al problema de drogas ilícitas en el posacuerdo 


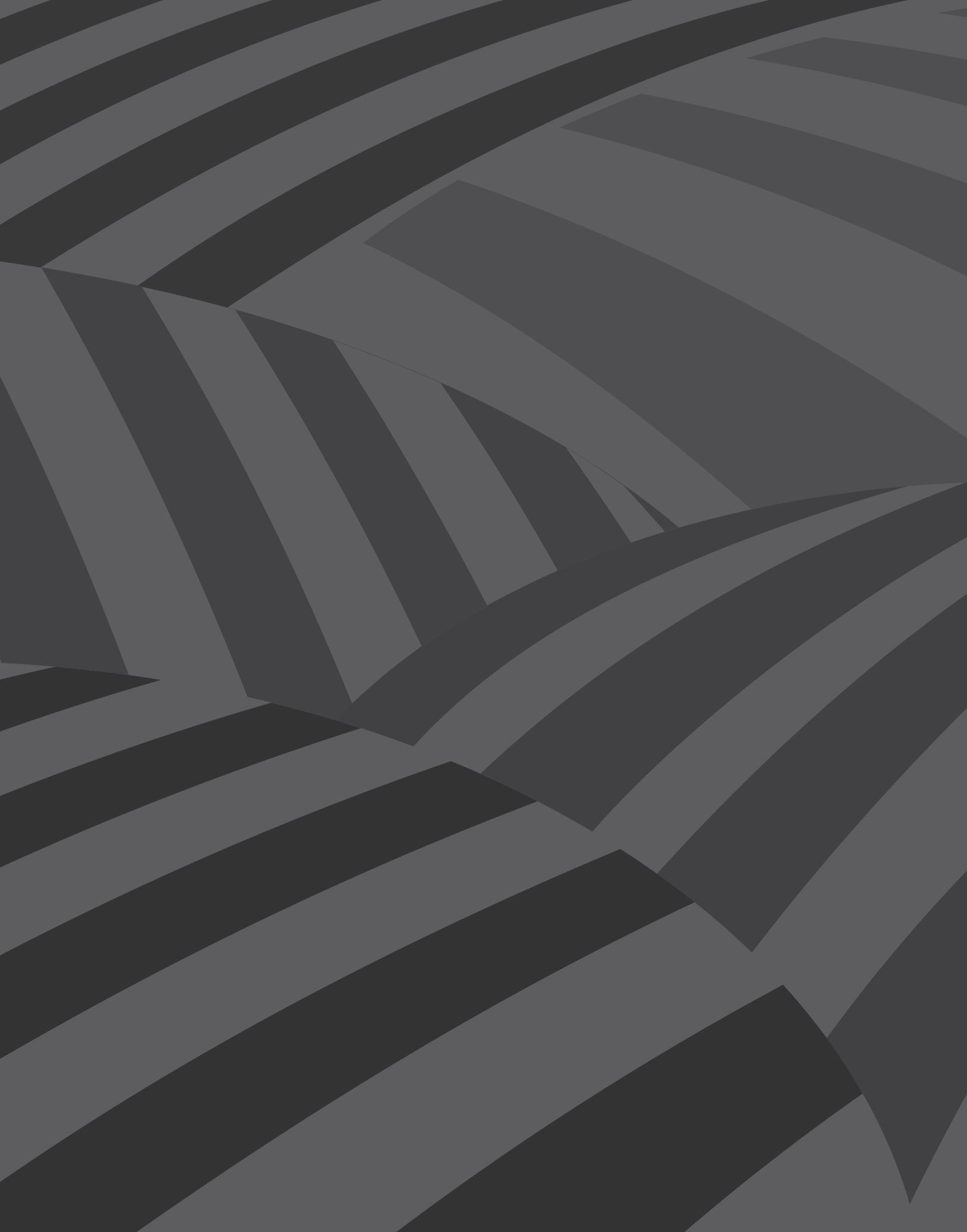




\section{La paz imperfecta: \\ una mirada a los puntos de tierras, participación política y solución al problema de drogas ilícitas en el posacuerdo}

Por Felipe Daza Alfonso*

DOI: https://doi.org/10.54118/controver.vi217.1239

Resumen: Uno de los hitos más relevantes en la historia reciente de Colombia es seguramente la firma del Acuerdo de Paz (2016), hecho que condujo al principio de la terminación del prolongado conflicto armado interno con la guerrilla más antigua de América Latina: las FARC-EP ${ }^{1}$. Con sus aciertos y tropiezos, el balance de su implementación puede ser agridulce. Por un lado, existen avances verificables en cada uno de los puntos eje del Acuerdo, aunque con varias particularidades. Por otro, haciendo una lectura general, cuatro años después del inicio de su ejecución, se puede evidenciar que este también ha sido un factor distanciador entre la sociedad colombiana. El análisis de este artículo se centró en tres de los seis puntos acordados, logrando un mayor detalle para cada caso.

Palabras clave: Acuerdo de Paz, paz positiva, paz negativa, conflicto armado, territorio.

\section{Imperfect Peace: a Review to Land, Political Participation, and Solution to the Problem of Illicit Drugs in the Post-agreement}

Abstract: One of the most relevant milestones in the recent history of Colombia is surely the signing of the Peace Agreement (2016), a fact that led to the beginning of the end of a prolonged internal armed conflict with the oldest armed group in Latin America, the FARC-EP. With its successes and failures, the balance of its implementation can be bittersweet. On the one hand, there are verifiable advances in each of the central points of the agreement, although with several peculiarities. On the

* Politólogo de la Universidad del Rosario. Estudiante de la Maestría en Desarrollo Rural de la Facultad de Agronomía de la Universidad de Buenos Aires, Argentina. Correo electrónico: felipedazaa@gmail.com

1 Fuerzas Armadas Revolucionarias de Colombia-Ejército del Pueblo. 
other, making an overview, four years after the beginning of its implementation allow us to see that the agreement has been a distancing factor among Colombian society. The analysis is focused on 3 of the 6 agreed points, achieving a greater detail for each case.

Keywords: Peace Agreement, positive peace, negative peace, armed conflict, region

Cómo citar este artículo: Daza Alfonso, Felipe (2021). La paz imperfecta: una mirada a los puntos de tierras, participación política y solución al problema de drogas ilícitas en el posacuerdo. Revista Controversia, 217, 165-218.

Fecha de recepción: 28 de febrero de 2021

Fecha de aprobación: 25 de mayo de 2021

\section{Introducción}

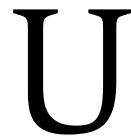

no de los hitos más relevantes en la historia reciente de Colombia es seguramente la firma del Acuerdo de Paz (2016), hecho que condujo al principio de la terminación del prolongado conflicto armado interno con la guerrilla más antigua de América Latina: las FARC-EP. Con sus aciertos y tropiezos, el balance de su implementación puede ser agridulce por distintas razones. Por un lado, existen avances verificables en cada uno de los puntos eje del Acuerdo, aunque con varias particularidades. Por otro, haciendo una lectura general, cuatro años después del inicio de su puesta en marcha, se puede evidenciar que este también ha sido un factor distanciador entre la sociedad colombiana.

Antes de adentrarse en una mirada detallada de los avances de cumplimiento del Acuerdo, vale la pena hacer una reflexión en torno a cómo se entiende y se busca la paz, especialmente cuando se observa que en nuestra sociedad se puede percibir un imaginario de paz inalcanzable, producto del recrudecimiento de la violencia en varias regiones del país. Aparecen imágenes desesperanzadoras que nos hacen preguntarnos si estamos retrocediendo en ese camino que llevaría a alcanzar una paz estable y duradera. 
Abordar el concepto de paz es una tarea compleja, por cuanto nos hallamos en presencia de un término polisémico y cuya definición está cargada de historia (Harto, 2016). A pesar de la amplia diversidad de significados del término paz (existen varias acepciones), un punto de partida son las definiciones de la paz como la ausencia/reducción de todo tipo de violencia, o la paz como transformación creativa y no violenta del conflicto (Galtung, 2003). De la primera definición se podría decir que está orientada hacia la violencia, siendo la paz la negación de esta. La segunda se desarrolla más en torno al conflicto, entendiendo que este puede transformarse, ya sea de manera no violenta o a través de la creatividad.

Estas premisas serán orientadoras en el desarrollo del documento, debido a que se entrelazan con los conceptos de: paz negativa (restringida) y paz positiva (holística) ${ }^{2}$. La primera se refiere a la superación de tres formas de violencia: directa, estructural y cultural. En esta la posibilidad de un conflicto es latente ${ }^{3}$. Frente a la segunda, esta se relaciona con lo que Galtung (2003) denomina el "despliegue de la vida”. Ambas ideas de paz son complementarias, ya que es importante alcanzar un primer estadio en el que la ausencia de los tres tipos de violencia posibilite la construcción de un tejido, y de estructuras sociales y culturales sólidas, cuyo sostén sea la justicia social y la plenitud de los derechos humanos.

2 El concepto de paz positiva ejerce su mayor influencia dentro de los investigadores europeos y en países en vía de desarrollo, resaltando al noruego Johan Galtung. El concepto de paz negativa tiene una mayor aceptación entre los investigadores norteamericanos, destacando a Kenneth Boulding (Stephenson, 1999).

3 “La paz entendida como 'no guerra' puede definirse como el estado en el que se encuentran grupos políticos entre los cuales no existe una relación de conflicto caracterizada por el ejercicio de una violencia durable y organizada. De esto se deriva que: a) Dos grupos pueden tener entre sí un conflicto sin estar en guerra, ya que el estado de paz no excluye el conflicto, sino solo el conflicto que se conduce mediante el ejercicio de la violencia durable y organizada; b) Dos grupos políticos no deben considerarse en estado de guerra si en sus relaciones se verifican casos de violencia esporádica, como por ejemplo los incidentes de frontera” (Bobbio, citado en Harto, 2016). 
Esta infraestructura de paz $z^{4}$ aporta a que se pueda llegar a las transformaciones esperadas (o anheladas), aunque esto depende de la promoción y construcción de un proyecto social que cultive sentimientos apropiados de empatía y amor que logren su estabilidad en el tiempo (Nussbaum, 2017). En este sentido, la búsqueda de la paz positiva representaría el faro que guía las acciones e iniciativas para alcanzar este ideal de paz, tranzando un camino en el que se acojan principios como la justicia social, una democracia ampliamente participativa y una convivencia enmarcada en una sociedad heterogénea que privilegie el respeto y la inclusión de los actores en los distintos procesos sociales.

Otras miradas sobre la idea de paz pueden tomarse como referente, como lo es el caso de la ahimsa, un término sánscrito que hace alusión a "no deseo matar”, "no hacer daño”, "no-violencia” (Román, 2006). Acuñado por Galtung (2003), Gandhi desarrolla este concepto más allá de la no-violencia, pues es el respeto por la justicia en todos sus ámbitos, basándose en una relación humana guiada y regulada por la fuerza del amor, el que puede traducirse en empatía. La relación entre la paz positiva y la idea de ahimsa brinda una mayor profundidad a este concepto, entendiendo que a esta no se llega después de la guerra y la violencia y es un fin en sí mismo (propio de la paz negativa), sino que es la base sobre la que se construye el tejido social que se resiste a una situación de conflicto. Vera Grabe, mujer exguerrillera promotora de paz, recuerda la importancia de ganar una actitud abierta para mirar con ambos ojos: el que ve la complejidad de la violencia y el que ve la riqueza de la paz (Fisas, 2006).

4 La infraestructura de paz se define como el "conjunto de espacios interconectados e institucionalizados, con responsabilidades asignadas por las partes del conflicto, mediante las cuales esas, junto con otros actores, construyen la paz y la sostienen en el tiempo" (Pfeiffer, citado en CinEP/PpP, 2016). 
Cabe preguntarse en este punto, qué modelo de paz deseamos y cómo podemos alcanzarlo. Una mirada en retrospectiva ayudará a poner en contexto esta pregunta.

\section{Revisión empírica de la concepción de paz}

En Colombia los procesos de paz han buscado una reconstrucción de país que responda al anhelo y la necesidad imperativa de encontrar una salida pacífica a estas situaciones que limitan el desarrollo territorial y comunitario. Quizás la ausencia de una voluntad determinada a cambiar la realidad (en sus distintas dimensiones) del país haya aportado de manera significativa al recrudecimiento de la violencia. Un ejemplo de esto pueden ser los frustrados intentos de paz que empezaron a gestarse en la segunda mitad del siglo XX y que pretendían generar cambios de fondo en las relaciones conflictivas entre las agendas desarticuladas del nivel central y las necesidades territoriales. Sin embargo, estos se vieron truncados en razón de que fueron concebidos desde el punto de la desmovilización de grupos al margen de la ley para garantizar el statu quo.

Se tienen al menos siete intentos de paz desde esta época, con pocos aciertos y un cúmulo de errores en la forma como se planteaba la salida del conflicto. El abordaje del concepto de paz negativa ha mostrado tener resultados en temas como la contención de grupos armados y la posterior disminución de los índices de violencia letal en los territorios con alta complejidad social. Este es el caso del Acuerdo de Paz, cuyos esfuerzos en sus inicios contribuyeron a una reducción de la violencia y a la reincorporación a la sociedad de 13000 antiguos integrantes de la extinta guerrilla FARC-EP (Reuters, 2021), pero al mismo tiempo han sido insuficientes en su objetivo de transformar los territorios en donde las dinámicas de conflicto son latentes.

La paz positiva, concepto que se tomará en principio como referente en este artículo y que se entrelaza con el de paz territorial, planteado en las 
discusiones en La Habana, implica no solo un presunto proceso de desmovilización (que para las FARC-EP no se dio) y desarme, sino también incluye una serie de aspiraciones y emociones que permitan cambiar los factores de reproducción de la violencia. La paz territorial - tomando el discurso del entonces alto comisionado para la paz Sergio Jaramillo en la Universidad de Harvard (2013) —, se define a partir de tres elementos: instituciones que garanticen los derechos de los colombianos en todo el territorio, reconociendo que el conflicto armado ha sido desigual en las regiones del país; participación y movilización ciudadana (abajo hacia arriba); y una nueva alianza entre el Estado y las comunidades; se incluye un cuarto elemento desarrollado por Aunta y Barrera (2016): mejorar y promover las capacidades comunitarias, entendidas como un conjunto de prácticas que responden de manera creativa a la dinámica de conflicto y cuyo fin es la adaptación y la supervivencia.

La paz territorial se enmarca en una mirada que incluye las nociones de paz negativa y positiva. Esta inicia cuando quienes hacían la guerra deciden dejar las armas y se ven inmersos en un proyecto de sociedad que propende por la participación activa de los ciudadanos en los cuatro ámbitos señalados, con el ánimo de mejorar las condiciones de vida propias y de sus entornos, dentro de ese proyecto que se llama la construcción de paz.

Esta nueva concepción de paz con enfoque territorial le apuesta a la transformación de las subregiones donde históricamente ha habido presencia de conflicto armado, espacios en los que han tenido injerencia una variedad de actores, legales e ilegales, con un impacto visible a lo largo del territorio colombiano (rural y urbano). Más adelante se ahondará en la reflexión sobre la paz buscada, entendiendo la complejidad de las relaciones sociales y reconociendo el carácter imperfecto de los modelos que regulan el comportamiento humano. 


\section{Breve cronología de la implementación del Acuerdo de Paz}

Los primeros dos años de posacuerdo se enfocaron en temas como el cese al fuego definitivo, la dejación de armas, la adecuación institucional para la paz, y los planes y programas que en el Acuerdo se contemplaron. Asimismo, en el Plan Marco de Implementación ${ }^{5}$ (PMI) se pueden identificar unas categorías en las que se encuentran las disposiciones del Acuerdo según la fecha de finalización asignada para cada indicador, clasificándolos en compromisos de corto plazo (2017-2019), mediano (2020-2022) y largo plazo (2023-2031) (Kroc, 2020).

De acuerdo con el cuarto informe del Kroc Institute for International Peace Studies (KIIPS, 2020), ha habido avances significativos en la implementación del Acuerdo frente a las disposiciones de corto plazo: $25 \%$ con nivel de cumplimiento completo, $15 \%$ con nivel intermedio y $34 \%$ con un mínimo de cumplimiento (figura 1). Muestra de lo anterior es que la mayoría de los compromisos cumplidos (corto plazo) pertenecen al punto 3 "Fin del conflicto”, y están relacionados con el cese al fuego y de hostilidades, la dejación de armas y la reincorporación de las FARC-EP a la vida civil.

Llaman la atención en este punto los resultados presentados por la Procuraduría General de la Nación en el segundo informe al Congreso sobre el estado de avance de la implementación del Acuerdo de Paz (2020), donde se refleja que, de los 84 indicadores del PMI que debieron estar cumplidos para el 2019, el 40 \% están pendientes. La figura 1 muestra el porcentaje de cumplimiento de los compromisos establecidos para el primer período (2017-2019) de la implementación, y según se observa, un $40 \%$ tienen un nivel completo o intermedio. Así, preocupa el $60 \%$ que registra un avance mínimo o ninguno.

5 “El PMI orientará las políticas públicas requeridas para el cumplimiento del Acuerdo Final (...) y facilitará su seguimiento por parte de las diferentes instancias dispuestas para este fin” (Gobierno de Colombia, 2018). 


\section{Figura 1. Implementación del Acuerdo de Paz en el período 2017-2019}

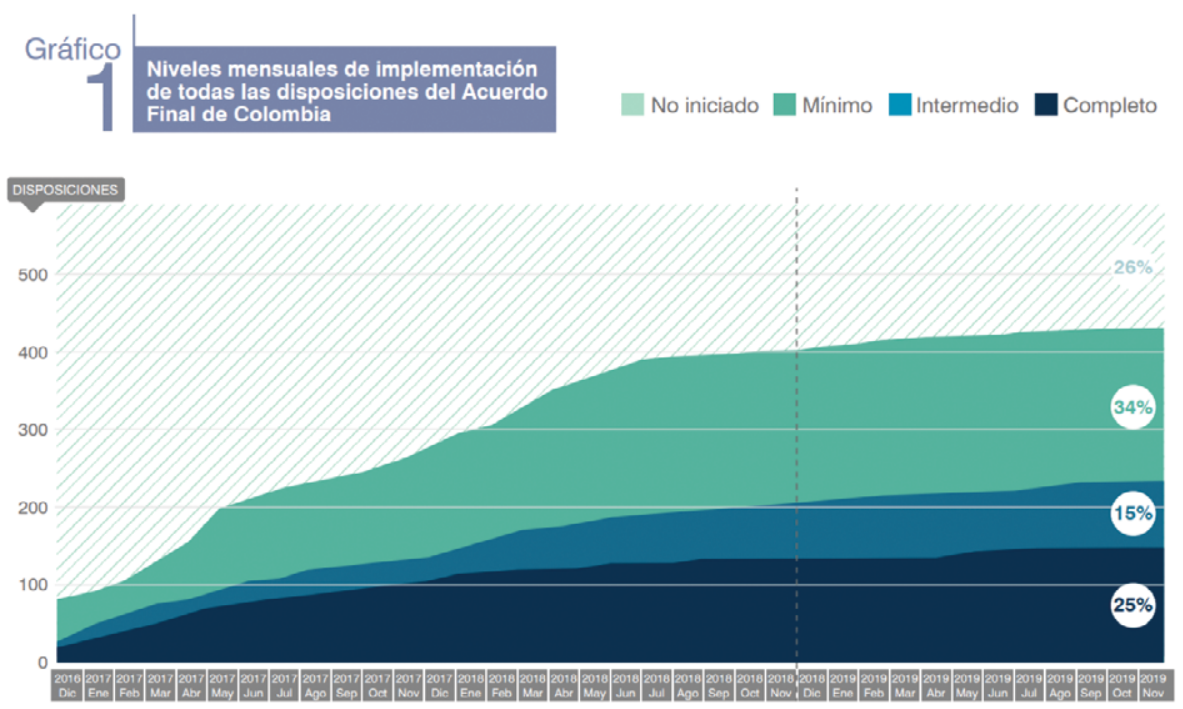

Fuente: Kroc Institute for International Peace Studies (2020).

En contraste con los dos primeros años, en el tercero y cuarto la ejecución y adecuación del Acuerdo han transitado a otras disposiciones de mediano y largo plazo, que requieren de procesos previos para ser completadas. Este tránsito ha implicado amplios retos en cuanto a la coordinación interinstitucional y su despliegue en los territorios, como a otros aspectos políticos asociados a la transición de gobierno y el nivel de compromiso con la paz. Aquí se destacan elementos esenciales como cimentar las bases y realizar ajustes institucionales, así como trabajar en estrategias de coordinación entre los actores implementadores, para garantizar las acciones previstas en el nivel territorial (Kroc Institute, 2021).

De esta manera, entre los principales desafíos que enfrentan las entidades implementadoras, además de la pandemia por CoviD-19, está lograr impulsar una agenda coordinada (interinstitucional e intersectorial) 
entre los niveles nacional-regional-local, donde se incluya una amplia participación de las comunidades locales.

Por otro lado, en términos relativos, existe un avance de aquellas disposiciones que pasaron de no iniciadas a iniciadas, observando que, según la figura 2, los mayores porcentajes de compromisos iniciados corresponden a los puntos 1 y 5, ambos vinculados con los Planes Nacionales de la Reforma Rural Integral y los mecanismos de justicia transicional (Kroc, 2021).

Figura 2. Avance de implementación 2019-2020

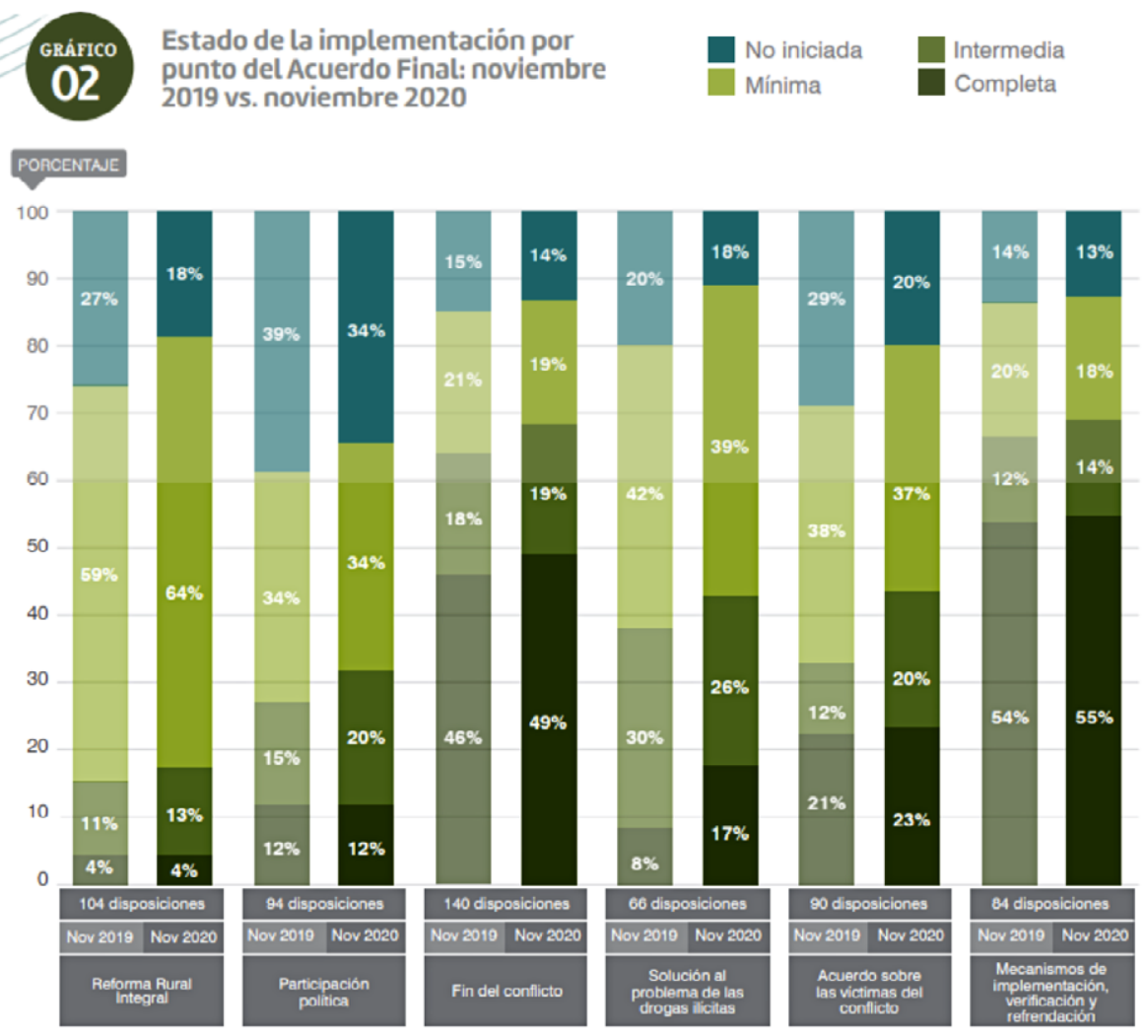

Fuente: Kroc Institute for International Peace Studies (2021). 
De la misma figura, también se resalta que los puntos 1 y 2 no tuvieron mayor variación durante el 2020 y, en el punto 4, a pesar de haber un avance en las acciones completadas, aún prevalecen cifras que generan alerta, especialmente con el Programa Nacional Integral de Sustitución de Cultivos Ilícitos (PNIS), el cual, según el Kroc Institute (2021) tiene el $17 \%$ de los compromisos sin iniciar, el $37 \%$ en un estado mínimo de avance, $31 \%$ en nivel intermedio y el $14 \%$ completados.

A cuatro años de la firma del Acuerdo Final, su puesta en marcha ha mostrado una dinámica de pocos cambios con relación al panorama en 2019. De las 578 disposiciones que tiene este, tan solo se observa un incremento de dos puntos porcentuales en las disposiciones implementadas completamente y en estado intermedio. Desde una mirada global de las acciones encaminadas a la construcción de paz (positiva), algunos factores dan cuenta de estas variaciones cuantitativas y que, además, representan un reto en su ejecución. Se encuentran los procesos de estructuración y coordinación que ha requerido el proyecto de paz, los cuales no se reflejan necesariamente de manera explícita en el texto del Acuerdo y, por ende, en los avances cuantitativos (Kroc Institute, 2021), como también está la ausencia de acciones dirigidas a la ejecución de los compromisos suscritos.

Para el cumplimiento de estas disposiciones, será de suma importancia perfilar estrategias que vayan de la mano de la construcción de una paz positiva, o al menos empezar a hacer hincapié en el ámbito territorial y poner de relieve la integralidad del Acuerdo, fundamental para el proyecto de paz territorial.

Otros retos trascendentales se enmarcan en una atmósfera caracterizada por el recrudecimiento de la violencia en varias regiones del país, dentro de las que se encuentran aquellas más afectadas por el conflicto armado. En consecuencia, no es raro escuchar historias de amenazas, asesinatos selectivos, masacres y otras formas de violencia en detrimento de los 
proyectos territoriales de defensores de derechos humanos o de personas que lideran procesos ambientales y sociales, sin desconocer el riesgo de las personas en proceso de reincorporación. Sumado a esto, están las limitaciones que ha supuesto la pandemia, particularmente en el desarrollo de una agenda de paz participativa, entendiendo que el proyecto de construcción de paz implica un trabajo mancomunado con las comunidades y las organizaciones locales.

Con base en este panorama general de implementación, a continuación se profundizará en los puntos de la Reforma Rural Integral (RRI), participación política y solución al problema de drogas ilícitas, resaltando su carácter urgente y necesario de cara a las transformaciones estructurales del campo y de una ampliación democrática, sin desconocer los demás puntos del Acuerdo, los cuales son integrales a la búsqueda de una paz con justicia social.

\section{Hacia un Nuevo Campo Colombiano: Reforma Rural Integral}

La lucha por la tierra ha sido un factor de exclusión social y económica de los/as pobladores/as rurales en el país. Al hacer una revisión general de la historia del conflicto armado en Colombia, se puede rastrear que este ha estado asociado directamente con la tierra y su acceso inequitativo. Adicional a lo anterior, en el camino del conflicto armado se fueron incluyendo otros elementos relacionados con problemas socioambientales y cultivos de uso ilícito. Esta dinámica tuvo un efecto que produjo varias olas de desplazamiento en el país, acompañado, en muchos casos, por procesos de acumulación y acaparamiento de tierras.

Con este contexto, no es difícil entender que las políticas rurales y la regulación de las estructuras agrarias estén en la base de las prioridades de una agenda de construcción de paz en Colombia (Sánchez, 2017). Aquí se reflejan las deudas estatales con los habitantes rurales del país, 
por lo que se hace sumamente importante una discusión política que lleve a saldar esta deuda histórica y genere transformaciones de fondo en las dinámicas de las relaciones que se tienen con la tierra, caracterizadas por la inequidad en su distribución, una baja formalización y un sin número de conflictos de distinta índole originados en el uso y tenencia de la tierra: interculturales, interétnicos, intraétnicos o asociados al modelo de desarrollo.

Este contexto nos lleva a pensar en la importancia de abordar el Acuerdo de manera holística, resaltando la búsqueda de una paz que se construya bajo la premisa de la justicia social (positiva), en la cual deberá existir un mayor acercamiento institucional a las regiones, especialmente a aquellas con altas complejidades sociales. Cabe mencionar que el 99,6\% del territorio colombiano está conformado por áreas rurales y tan solo el $0.36 \%$ corresponde a las zonas urbanas de las principales ciudades del país (Instituto Geográfico Agustín Codazzi [IGAC], 2015). Estas cifras contrastan con el fenómeno de migración rural hacia los centros urbanos, que ha cobrado un nuevo impulso debido al decaimiento del sector agrario, a la concentración de la propiedad rural, a la situación de pobreza en los ámbitos rurales, y a la violencia generada por grupos al margen de la ley y su subsecuente desplazamiento. El Censo Nacional de Población y Vivienda (DANE, 2018) estableció que la distribución de la población por ubicación es: 77,1 \% en cabeceras municipales versus $24 \%$ en centros poblados y rural disperso.

En su primer punto, el Acuerdo planteó la Reforma Rural Integral (RRI), cuyo objetivo está encaminado a la transformación de la realidad rural del país. Esta se encuentra orientada a "integrar las regiones al desarrollo, erradicar la pobreza rural y asegurar el pleno disfrute de los derechos de la ciudadanía en las zonas rurales" (Presidencia de la República, 2016). De esta manera, la RRI está basada en una concepción de desarrollo rural que permita una provisión efectiva de bienes públicos y servicios sociales necesarios para los/as habitantes de la ruralidad, 
además de un fortalecimiento del modelo de agricultura familiar. Ambos elementos claves para la construcción de paz desde un enfoque territorial.

La RRI tiene cuatro pilares, a saber: dar un salto cualitativo y cuantitativo (calidad y cantidad) en el acceso y uso de la tierra, el establecimiento de Programas de Desarrollo con Enfoque Territorial (PDET), planes nacionales en el mundo rural que permitan la reducción radical de la pobreza y el derecho a la alimentación.

\subsection{Acceso a la tierra}

Cuatro años desde el inicio de la implementación del Acuerdo dejan entrever algunos resultados preliminares y un balance que, como se mencionó al principio, puede ser agridulce. Para el caso de acceso a la tierra y su uso, se resalta el avance en la definición de la política de ordenamiento social de la propiedad rural; la constitución del Fondo de Tierras, con un compromiso de 3000000 de hectáreas en el Acuerdo y que, según la Agencia Nacional de Tierras (ANT, 2021), cuenta con 138.633 hectáreas; los procesos de formalización de baldíos; y los mecanismos alternos de acceso a la tierra (Procuraduría General de la Nación, 2020). No obstante, existe un rezago en los procesos agrarios y en las distintas solicitudes de formalización de tierras, lo cual ha llevado a la ANT a focalizar gran parte de su trabajo en cotejar información de carácter técnico, así como en la sistematización y digitalización de los documentos que componen los expedientes. Esta es una situación que ha limitado los avances en el cumplimiento de las metas relacionadas con el acceso a la tierra.

De acuerdo con la información brindada por el Observatorio de Tierras Rurales de la ANT (2021), de territorios baldíos se han adjudicado 1144376 hectáreas, beneficiando a 46867 familias; por otro lado, las adjudicaciones a personas naturales en zonas PDET alcanzan las 302560 hectáreas; y para el caso de las comunidades étnicas, un total de 854239 hectáreas regularizadas, las cuales han beneficiado a 5757 familias. 
Es importante poner estos datos en contexto, ya que en el reporte sobre formalización de bienes baldíos, fiscales patrimoniales, y sobre las entregas de subsidios a campesinos y comunidades étnicas (correspondientes a 1965 535,3 hectáreas), llama la atención que el 55 \% (1 088 985 hectáreas) corresponda a adjudicaciones de baldíos con ocupaciones previas, que se hicieron antes del año 2000 y entre los años 20002016 a personas naturales (Procuraduría General de la Nación, 2020). En estricto sentido, esta gestión no correspondería en esencia al compromiso agrario del subpunto 1.1 del Acuerdo de Paz, sino más bien a un reporte de actuaciones que se enmarca en compromisos adquiridos en vigencias anteriores.

La Procuraduría General de la Nación (2021), en su último informe sobre acceso a tierras y uso del suelo rural, advierte sobre el millón de hectáreas ingresado al Fondo de Tierras. Esto debido a que, según el organismo de control, solo 2253 predios correspondientes a 96471,1 hectáreas tienen a la fecha la condición de adjudicables, es decir, menos del $10 \%$. Además, el mismo informe reporta que el número de hectáreas adjudicadas a través del Fondo (30 318,6 ha), desde el inicio de la implementación del Acuerdo, representa el $1 \%$ del total esperado. La apuesta en este punto deberá estar enfocada en adelantar un plan de choque frente al rezago de la entidad en los procedimientos que adelanta, con el propósito de poder dotar al Fondo de Tierras y garantizar el cumplimiento de lo pactado en el acuerdo.

Preocupa la situación de los/as labriegos/as del país, respecto a la cual la Corte Constitucional en la sentencia C-077 de 2017 pide declarar el estado de cosas inconstitucionales para acudir a mecanismos que protejan los derechos de los campesinos en materia de acceso a tierras. Aquí se denuncia el sistema de estímulos e incentivos presentados por la Ley 1776 de 2016 (Ley Zidres), que favorece los proyectos productivos de agroindustria, alejándose del modelo de agricultura familiar y limitando las opciones del campesinado frente al desarrollo de actividades productivas. 
Algunas cifras tomadas del Censo Nacional Agropecuario de 2014 permiten inferir que la tierra no es del campesinado. De acuerdo con el DANE (2014), en Colombia hay 2370099 predios rurales dedicados a la actividad agropecuaria. De esa cifra, 1669287 tienen menos de cinco hectáreas. Esa tierra que ocupan los pequeños productores corresponde al $2 \%$ del área rural del censo agropecuario. En contraste, hay 5842 predios de más de mil hectáreas que abarcan el 73,8 \% de la tierra productiva. Esta penosa realidad lleva a que Colombia sea uno de los países con mayor concentración de tierra en el mundo, con un índice de Gini del 0,89 \%, mayor al promedio en Latinoamérica, que de acuerdo con Alzate (2020), es del 0,79\%.

Un elemento esencial que busca subsanar esta realidad es el Subsidio Integral de Acceso a Tierras (SIAT), el cual fue concebido en el Acuerdo como "un subsidio integral para la compra de tierras por parte de las personas beneficiarias (..), en las zonas priorizadas" (Gobierno Nacional y FARC-EP, 2016, p. 15). Con tres años de retraso para su reglamentación, en el último semestre de 2020 el Gobierno formalizó este mecanismo a través del Decreto 1330 de 2020, con lo cual se espera que aumente el acceso y la formalización de la tierra en el país. Por otro lado, dos políticas distintas pero integrales para fortalecer el acceso a la tierra son: el ordenamiento social de la propiedad rural (OSPR) y el catastro multipropósito.

El OSPR es un mecanismo de planificación y gestión que explora la distribución equitativa de la tierra, el acceso inclusivo y aporta una mayor capacidad de gestión sobre la propiedad en el campo, lo cual hace necesarias medidas de carácter administrativo y legal para su efectivo desarrollo. Sin embargo, más allá de su función, desde la institucionalidad se mantiene la priorización de un modelo de atención por demanda, pues la focalización de los municipios para la ejecución de los Planes de Ordenamiento Social de la Propiedad Rural (POSPR), liderada por el Ministerio de Agricultura y Desarrollo Rural, se concentra en un 
bajo número de estos (56 frente a 1122 entidades administrativas locales), acompañado del hecho de que solo existe un municipio en el que esta política se encuentra desarrollada e implementada: Ovejas (Sucre). Además, se advierte que dentro de estos planes no se han incorporado las sugerencias de la Misión Rural (2015), relacionadas con el ordenamiento productivo y la función social y ecológica de la propiedad.

Con respecto a la política catastral, planteada como una ventana de oportunidad para fortalecer y modernizar al Estado desde el ámbito local, a pesar de tener un impacto positivo sobre las comunidades rurales (seguridad jurídica sobre la propiedad rural y acceso a créditos y programas del Gobierno), sus avances se han centrado en marcos legales, aunque con grandes obstáculos de carácter administrativo. La actualización catastral de los 170 municipios PDET tiene una meta de algo más de 39000000 de hectáreas y a 2019 se había logrado la actualización de dos municipios: La Jagua de Ibirico en el Cesar y Ovejas en Sucre, que representan 121595 ha, correspondientes al 0,31\% del área total de los municipios. En el 2020 se inició un trabajo de campo en Rioblanco y El Guamo, sur del Tolima; Córdoba, sur de Bolívar; Fonseca, Sierra Nevada-Perijá; así como en Cumaribo, Vichada, que no es PDET, pero si PISDA $^{6}$ (CINEP/PPP-CERAC, 2021).

El Gobierno nacional debe visualizar y proyectar la actualización del catastro como una inversión con alto retorno. El incremento de la capacidad fiscal de los municipios para el cobro del impuesto predial puede generar mayores inversiones en temas relacionados con el Acuerdo ${ }^{7}$, como los PDET. También aporta a la debida administración de las zonas de conservación ambiental en el país, mitigando conflictos asociados a

6 Plan Integral Municipal y Comunitario de Sustitución y Desarrollo Alternativo.

7 Un ejemplo es el caso del municipio de Ovejas, Sucre, donde se llevó a cabo el piloto de ordenamiento de la propiedad mientras se actualizaba el catastro. Como resultado de la formalización de predios y el mejoramiento de la información, la PGN (2020) reportó que el recaudo del impuesto predial aumentó tres veces más en un año. 
sobreposiciones entre figuras territoriales como resguardos indígenas, zonas de reserva campesina, parques nacionales naturales, entre otros.

Este panorama es el reflejo de lo que, en palabras de Francisco Gutiérrez Sanín (2921), es "una concentración absolutamente obscena de la tierra” (Noticias Caracol, 2021). Esto quiere decir que no solo es socialmente injusta, sino que también termina por socavar las posibilidades de un verdadero desarrollo rural, en parte, debido a que cargamos con el lastre de una reforma agraria frustrada que advierte serias dificultades para el acceso a la tierra por parte de los/as actores rurales.

\subsubsection{Conflictividades territoriales}

En este acápite se pretenden dar algunas pistas para entender el problema de la tierra en Colombia, y su manifestación particular en lo que más recientemente se han denominado conflictos territoriales, una expresión que ha cobrado una relevancia especial en el debate público, y que utilizan tanto la institucionalidad como los organismos multilaterales, la academia y también algunos procesos sociales.

Es apenas sensato que el sentido de la expresión conflictos territoriales revista distintos matices, como también divergencias, dependiendo del lugar de enunciación. Incluso, existen quienes prefieren optar por términos como tensiones o desarmonías en lugar de conflictos, como es el caso de algunas comunidades indígenas (ejemplo: el pueblo totoroez del Cauca). Tradicionalmente, en la literatura sobre conflictos, el concepto de conflicto territorial está ligado a estudios relacionados con las disputas entre los Estados por el territorio.

No obstante las nuevas y aceleradas dinámicas territoriales se dan contextos en los que, desde la sociología de la globalización, se desestabiliza la jerarquía tradicional centrada en el Estado-nación, pues se reconoce el papel de lo subnacional en un mundo globalizado (Sassen, 
2007). Lo anterior hace manifiesta la necesidad de ampliar el marco de análisis para hacer una lectura de estas realidades subnacionales.

En la escala subnacional ${ }^{8}$ es posible identificar, al menos, cuatro grandes aproximaciones al análisis en los contextos de la ruralidad colombiana: conflictos socioambientales ${ }^{9}$, conflictos por el uso y tenencia de la tierra, conflictos interétnicos e interculturales y los conflictos territoriales. Todos estos recurrentes en la realidad territorial del país. En este sentido, vale la pena hacer una reflexión en torno a cómo se entienden los conflictos. Estos, como primera idea, son inherentes a nuestros contextos sociales. Autores como Estanislao Zuleta plantean que, "una sociedad mejor es una sociedad capaz de tener mejores conflictos. De reconocerlos y de contenerlos. De vivir no a pesar de ellos, sino productiva e inteligentemente en ellos" (2015, p. 25).

Hoffman (2001) aborda las conflictividades desde las reivindicaciones étnicas y territoriales de las comunidades afrocolombianas, quienes se apoyan en la reconstrucción de su historia y de la memoria colectiva que legitima su pretensión de hablar y actuar como actor participante sociedad nacional. Identifica cuatro tipos de conflictos relacionados con el territorio: conflictos internos (el territorio se vuelve objeto de competencia dentro de las mismas poblaciones); conflictos con vecinos (interétnicos); conflictos por conflicto armado; y conflictos por pretensiones territoriales de grandes agentes económicos (relacionados con megaproyectos de explotación del territorio).

Por otro lado, los procesos organizativos también han sido un marco de reflexión en torno a las tensiones territoriales. El Paro Nacional Agrario del 2013 fue determinante para poner de relieve (en el debate público)

8 Fenómenos de escala global insertos en espacios subnacionales.

9 Partiendo del punto que la naturaleza no debe considerarse como un agente externo a la sociedad humana, se da más bien en un entorno de coevolución. 
la necesidad de entender los antagonismos y situaciones conflictivas en el campo colombiano. Producto de esto surgió la Cumbre Agraria, Campesina, Étnica y Popular (CACEP), planteada como un espacio de convergencia de procesos organizativos de las comunidades rurales. La CACEP, en 2015, adelantó un proceso de identificación y caracterización de conflictos territoriales, en un esfuerzo por entender y gestionar dichas querellas. Una de las principales conclusiones de este proceso es que las situaciones de conflicto que se viven en los territorios donde distintas organizaciones hacen presencia, son el resultado de una variedad de visiones y formas de entender y relacionarse con el territorio.

Desde el Instituto de Estudios Interculturales (IEI), de la Universidad Javeriana de Cali, se ha trabajado en la identificación de las conflictividades territoriales, logrando tipificarlas. Su rol en la gestión de las tensiones por el uso y tenencia de la tierra ha sido significativo, incluso ha aportado a la forma como desde las instituciones se abordan estas situaciones con un enfoque diferencial, y promoviendo el diálogo intercultural. En la figura 3 se observa el mapa con la distribución geográfica de los conflictos identificados por la entidad.

La ANT, con sus aciertos y tropiezos, ha ido adecuando su gestión de cara a las conflictividades en la ruralidad. Para el 2021, la entidad reporta alrededor de 138 conflictos territoriales caracterizados en todo el territorio nacional. El tipo de conflicto territorial más recurrente en la ruralidad es el intercultural, definido como aquel que se presenta entre comunidades campesinas y grupos étnicos. A nivel nacional, se identificaron 51 casos que se enmarcan en este tipo de conflicto, lo cual representa casi el $35 \%$ del total. El segundo tipo de conflicto más representativo es entre una comunidad con un particular, con 31 casos que significan el 21,2 \% del total. En tercer lugar, se ubican aquellos de carácter interétnicos, es decir, entre distintas comunidades o grupos étnicos, con 22 casos $(15,06 \%$ del total). 
Figura 3. Mapa del tipo de conflictos identificados por el IEI

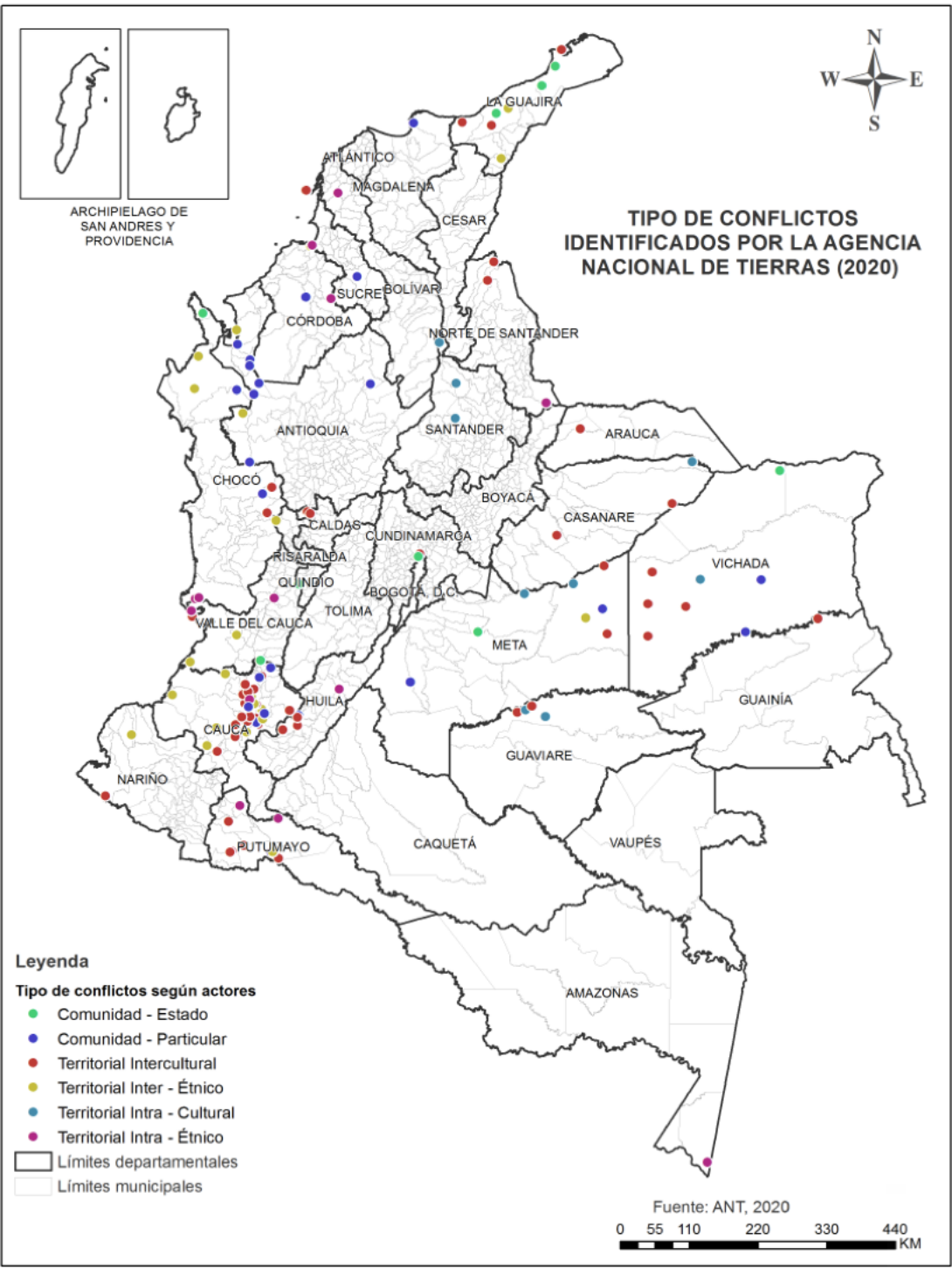

Fuente: Instituto de Estudios Interculturales (2020). 
Los principales retos se presentan con la interculturalidad y el ordenamiento territorial. Parte del trabajo que tiene que abordar el Estado frente a las conflictividades implica adentrarse en el génesis de estas, entendiendo que el OSPR tiene serios obstáculos cuando se miran con lupa las figuras territoriales y los conflictos que las entrelazan. Un buen ejemplo es el conflicto latente que existe actualmente en el departamento del Guaviare con la población indígena nukak, un pueblo nómada que lucha por su pervivencia y que actualmente no cuenta con garantías de retorno a su territorio. En este caso se habla de una sobreposición entre la zona de reserva campesina del Guaviare y el resguardo indígena nukak. Esta incertidumbre ha generado procesos de larga tensión entre ambas comunidades, sumado al hecho de la particular vulnerabilidad multidimensional del pueblo nukak, el cual afronta serios obstáculos que limitan la garantía plena de sus derechos territoriales, al menos, en el corto y mediano plazo.

Este ejemplo, como muchos otros, ha puesto sobre la mesa la importancia de una estrategia de diálogo intercultural y la necesidad de concertar con las comunidades los mecanismos alternativos de solución de conflictos, hecho que se contempla en el artículo 55 del Decreto 902 de 2017. En este punto se debe considerar la importancia de potenciar el papel de los conciliadores en materia de resolución de conflictos por uso y tenencia de la tierra, lo cual puede evitar las vías de hecho ${ }^{10}$. No menos importante es pensar en un modelo de justicia agraria funcional a las controversias en esta materia. El Gobierno nacional presentó al

10 Los mecanismos alternativos de solución de conflictos son una alternativa a la justicia formal, que buscan resolver de manera idónea las controversias que se puedan generar entre las partes. Cualquier persona puede hacer uso de ellos y tiene distintas alternativas según sus preferencias o necesidades. Estos ofrecen una propuesta distinta a un enfrentamiento: buscan que las partes encuentren un punto medio en el cual no existe la figura de un vencedor y un vencido, sino centros de diálogo por cuenta propia o con la ayuda de un tercero, buscando el beneficio común y la satisfacción de los implicados. A diferencia del proceso judicial, las partes plantean la solución a sus diferencias de manera civilizada y pacífica (Gil, citado en Cabana, 2017). 
Congreso en el 2020 el Proyecto de Ley Estatutaria 134/2020C, que ya empezó su trámite y fue aprobado en segundo debate ${ }^{11}$. Será fundamental el seguimiento constante al trámite que surta en el Congreso, pues contiene metas ambiciosas que apuntan a una oferta de justicia rural en la totalidad de los municipios del país.

Afrontar la interculturalidad y los conflictos que surgen de este entramado de relaciones territoriales, lleva a reflexionar sobre la importancia de la concertación con los actores rurales y la búsqueda de mayores y mejores canales de comunicación en la relación Estado-comunidad, para establecer acuerdos en medio de la pluralidad de concepciones, trayectorias y principios de organización territorial.

\subsection{Programas de Desarrollo con Enfoque Territorial}

LOS PDET son una apuesta interesante para la construcción del desarrollo territorial desde los actores locales y sus organizaciones. Estos, además de buscar trasformaciones estructurales en el campo y en las relaciones comunidad-Estado, se plantean desde una mirada que privilegia el enfoque participativo en el que se busca que las acciones estatales sean producto de los acuerdos logrados entre las comunidades en distintos temas (organizativos, políticos, culturales, económicos), haciendo hincapié en el ámbito rural. En total son 16 subregiones focalizadas que conforman un nodo central en la implementación de la RRI.

La política de estabilización Paz con Legalidad del actual Gobierno ha mostrado, de manera mediática, un particular interés en este punto del Acuerdo, incluso se le ha acusado de limitar la RRI a los PDET, desconociendo aspectos que deben articularse con otros programas e iniciativas contempladas en el punto 1 . Algunos logros se han concentrado en el

11 Se propone en cumplimiento del punto 1.1.8 del Acuerdo de Paz. 
reconocimiento de las comunidades y sus organizaciones sociales, lo cual ha permitido un acercamiento institucional a las regiones.

La socialización, concertación y verificación de la hoja de ruta única (HRU) en la subregión del Catatumbo fue un ejercicio que permitió evidenciar la importancia de esta herramienta que entrelaza los planes y programas territoriales. Sin embargo, de acuerdo con la Secretaría Técnica del Componente Internacional de Verificación CINEP/PPP-CERAC (2021), esta HRU no identificó los espacios e instancias de participación, control y seguimiento, además, no es clara la forma en que se integran los instrumentos de planificación para esta zona, que de acuerdo con las disposiciones del Plan Nacional de Desarrollo (PND) son: los Planes de Acción para la Transformación Regional (PATR), los Planes para la RRI, los Planes Integrales de Sustitución y Desarrollo Alternativo (PISDA), los Planes Integrales de Reparación Colectiva (PIRCA) y el PMI.

Otra preocupación en cuanto al acceso a la tierra se relaciona con el hecho de que las zonas de alta importancia para la construcción de paz como el Catatumbo, Pacífico medio, sur del Tolima, Chocó, Putumayo, Pacífico y Frontera Nariñense, cuenca del Caguán y piedemonte caqueteño, y sur de Córdoba, es decir, ocho subregiones PDET, tienen una baja representación en el Fondo de Tierras (PGN, 2021). Aquellas que reportan mayor gestión son el sur de Bolívar y Arauca. Estos hechos cobran especial relevancia al entender y dimensionar la deuda histórica del país con cada región, por lo cual se hace un llamado a la necesidad del enfoque territorial.

Parte de la gestión del Gobierno se ha concentrado en la formulación de 16 PATR, que en esencia deberían construirse en aras de articularse con otros programas del Acuerdo. En consecuencia, lo que se puede percibir es una gestión de los PDET supeditada a los PATR, lo que derivó en un listado de 32000 iniciativas solicitadas por las comunidades, en su mayoría percibidas como responsabilidades cotidianas y básicas del Estado, con o sin Acuerdo (El Espectador, 2020). La gestión del Gobierno debe 
ir más allá de cubrir una serie de necesidades básicas. Al ser el Acuerdo un punto de inflexión en la historia reciente, su pretensión y alcance se plantean de cara a cambios de fondo en la estructura agraria del país.

La municipalización de las iniciativas que surgen de los PATR ha sido un elemento que le ha disminuido el enfoque territorial a los PDET. Darle un mayor énfasis al ámbito municipal puede llevar a que, en ausencia de apuestas que promuevan nuevas realidades regionales, el enfoque territorial se desdibuje y, por ende, las iniciativas de las subregiones difícilmente puedan llegar a concretarse. Adicionalmente, al tratarse en su mayoría de iniciativas municipales, estas dependen de la voluntad política y fiscal de los gobernantes locales, entendiendo que gran parte de los municipios PDET son de sexta categoría y esto repercute en la financiación de programas.

Difícilmente puede existir desarrollo territorial sin garantías de financiación de las apuestas estructurales de la RRI. Cuando se entra en contacto con las comunidades rurales y se indaga sobre cómo han visto el despliegue de los PDET, se puede observar, en principio, algo positivo: se han logrado afianzar las relaciones comunidad-Estado, aunque cabe resaltar que la participación comunitaria ha sido a través de la contratación de organizaciones sociales para completar muchas de las obras PDET. Al recorrer la ruralidad - hablo desde una experiencia personal por el departamento del Guaviare-, pareciese que la apuesta del Gobierno se ha concentrado en cemento, más allá de una verdadera apuesta participativa.

Lo anterior se puede sustentar en lo expuesto por líderes y lideresas en la Mesa Nacional de la Sociedad Civil, llevada a cabo en noviembre del 2020, donde se resaltan aportes como el de Magaly Belalcázar (lideresa), quien comenta que "los PDET se dedicaron al cemento, además de que en los informes de la Consejería del Posconflicto se detallan puentes peatonales, más de 500 horas de taller y otro, pero las mujeres rurales estamos lejos de ser reconocidas en esos programas” (Vásquez, 2020). 
Desde el enfoque de género, se resalta la inclusión de mujeres en los procesos participativos territoriales de formulación de los PDET. La Agencia de Renovación del Territorio (ART) creó y puso en marcha una estrategia de promoción de la participación de estas en la formulación de los PATR. A pesar de esta buena iniciativa, esta estrategia presentó limitaciones relacionadas con la ausencia de condiciones para que las mujeres accedieran de forma igualitaria a las discusiones, además de un vacío pedagógico que debilitó su participación por falta de conocimiento del proceso PDET (CINEP/PPP-CERAC, 2019). De cara a estas limitaciones, es necesario resaltar la importancia de la apertura a una mayor participación de las mujeres en estos procesos territoriales, sobre todo si se tiene en cuenta el rol de la mujer rural dentro de las dinámicas machistas afincadas en las estructuras comunitarias rurales, donde el jefe de hogar es el que usualmente asiste a los espacios de reunión y participa en la toma de decisiones.

También se han percibido fuertes críticas a las fuentes de financiación de los PDET, en parte a cargo del Sistema General de Participaciones (SGP), las cuales tienen restricciones constitucionales para su uso, es decir, provienen de las transferencias que por ley la nación debe realizarles a los entes territoriales. Esto significa que, básicamente, con o sin Acuerdo, los recursos del SGP van directamente a los municipios con una destinación específica, por lo cual no se están haciendo esfuerzos fiscales adicionales para nutrir los PDET.

Con relación a los Órganos Colegiados de Administración y Decisión (OCAD) y concretamente con el OCAD-PAZ, si bien en el 2020 se aprobó la Ley 2056 que busca fomentar la estructuración y aprobación de proyectos de inversión para la implementación del Acuerdo, se observa un desbalance en las inversiones realizadas en las subregiones PDET (CINEP/PPP-CERAC, 2021), puesto que no todas han sido beneficiadas en igualdad de condiciones, lo que podría contribuir al incremento de brechas de desarrollo territorial entre las subregiones. 
Con todo lo anterior, los PDET no pueden reducirse a su instrumentalización a través de los PATR ni mucho menos a iniciativas municipales que afectan seriamente su enfoque territorial. Será importante contar con una financiación que provenga de recursos "más frescos" que no dependan en su mayoría del SGP o el SGR. Muchas de estas inconsistencias, en ocasiones, son opacadas por gestiones que le han apuntado más a temas de infraestructura que a los cambios pretendidos con los programas, con lo cual, fortalecer la gobernanza territorial y el rol de la mujer rural, es esencial para la construcción de confianza en la relación Estado-comunidad.

\subsection{Planes Nacionales de la Reforma Rural Integral}

Problemáticas como pobreza o debilidad estatal no corresponden únicamente a los 170 municipios que se priorizaron en los PDET, con lo que los PNRRI buscan tener un mayor alcance para contribuir al cierre de brechas socioeconómicas en municipios "no- PDET". Estos planes fueron contemplados en una fase de transición de 15 años. Para febrero de 2021 se contaba con la aprobación de uno de los planes nacionales pendientes, llegando a un total de nueve de los 16 previstos. Se trata del Plan Nacional para Apoyar y Consolidar la Generación de Ingresos de la Economía Campesina, Familiar y Comunitaria (punto 1.3.3.3 del Acuerdo), adoptado mediante Resolución 209 de 2020 del Ministerio de Agricultura y Desarrollo Rural (CINEP/PPP-CERAC, 2021).

Algunas oportunidades de mejora dentro del análisis de los planes están encaminadas en la urgencia de concluir con la formulación y expedición de los PNRRI restantes. Es importante avanzar en la aprobación e implementación de los planes nacionales relacionados con temas como la salud rural y el derecho a la alimentación. Por lo anterior, se hace un llamado a la armonización de los PDET con los PNRRI, así como también a la aprobación de los nueve planes que aún no han sido adoptados por 
acto administrativo, subrayando que estos son necesarios para la HRU y el cierre de brechas entre el campo y la ciudad.

Dentro de lo expuesto en este primer aparte se resalta el hecho de buscar consensos entre los actores, ya sean aliados u opositores de las disposiciones de la RRI. Para ilustrar esta idea de negociación se pueden tomar como referente las dádivas que la administración Santos tuvo con sectores agroindustriales, donde se buscó darles un contentillo a empresarios a través de la aprobación de la Ley de las Zidres, que permite el desarrollo de grandes proyectos agroindustriales en terrenos baldíos, a pesar de que oficinas como la Unidad de Restitución de Tierras o el Alto Comisionado para la Paz se opusieran, al considerar que primero debía garantizarse una distribución de la tierra equitativa al campesinado. Lo que muestra esto es que "los gobiernos no son unidades homogéneas sino entes complejos y con múltiples agendas en su interior” (Migdal, citado en Arbeláez, 2020).

Con este balance de la RRI, la construcción de una paz positiva se puede ver, desde muchos aspectos, inalcanzable, sobre todo si se tiene en cuenta que los cambios (muchos estructurales) que el Acuerdo pretende son bastante ambiciosos (pero necesarios) y requieren de un compromiso completo del Gobierno nacional y de la sociedad, en general. Es conveniente que en el camino de alcanzar esta idea de paz se reconozca la complejidad de nuestras sociedades, ya que en ellas conviven sentimientos de miedo y conflictividad, pero también existen la cooperación y la empatía. Despertar las emociones y sentimientos adecuados para la construcción de paz implica generar confianza en los procesos e invita a la colaboración de la sociedad en su conjunto. Así, el camino hacia esa idea de paz completa (positiva) difícilmente se logra, si no se promueven emociones que deriven en una cohesión social bajo la premisa de la justicia social, lo cual podría representar una oportunidad para enfrentar el legado de los conflictos rurales. 


\section{Participación política: apertura democrática para construir la paz}

Democracia y participación política son conceptos afines, inclusive se podría pensar que son sinónimos. Difícilmente se puede considerar una democracia sin la participación de su ciudadanía, y de sus partidos y movimientos políticos. La participación es intrínseca a la democracia por cuanto se sustenta en el diálogo y la interacción entre los ciudadanos con los asuntos del Estado, como también la inclusión de fuerzas políticas y movimientos sociales cuyas garantías se den bajo principios como la transparencia, objetividad y equidad de género, además de poder construir y divulgar programas políticos.

La participación, como apertura democrática, ha sido un tema de debate, incluso desde la academia ha estado abierto el diálogo sobre los posibles modelos de democracia, esto es, entre la democracia representativa o la participativa. Asimismo, la participación política y ciudadana se han venido instalando de manera transversal en los discursos de distintos actores políticos. No obstante, actualmente persiste una crisis de legitimidad de la democracia y del rol de las instituciones, siendo este un factor que termina afectando el modelo de democracia participativa.

Por tal razón, esta apuesta de apertura de las instituciones y del espectro político encuentra una valoración positiva en la sociedad civil, aunque hay que resaltar que muchas discusiones no terminan materializándose en mecanismos de participación que puedan ser aplicables a la realidad en la cual se desenvuelven los regímenes políticos (Contreras y Montecinos, 2019). El caso colombiano ha tenido sus particularidades. Transcurrido un poco más de un cuarto de siglo desde la Constitución Política de 1991, aún se percibe una rigidez en el sistema de partidos que, hoy en día, continúa mutando. Para esto, el Acuerdo de Paz en su punto 2 "Participación Política: Apertura democrática para construir la paz” busca 
abordar la exclusión política, la cual se ha dado en contextos de violencia y bipartidismos que han llevado a una obstrucción de la inclusión de fuerzas y movimientos políticos alternativos.

Para este fin, este punto promueve mecanismos democráticos de participación ciudadana desde el nivel nacional hasta el local. Esto es de especial relevancia, dado que una mayor incidencia de los ciudadanos en los procesos de toma de decisiones fortalece la legitimidad de la democracia y le da un toque esperanzador a la construcción de paz. Por este motivo, la participación ciudadana es un principio transversal en el Acuerdo de Paz, contribuyendo al fin último de un Estado social de derecho y resaltando la búsqueda de la justicia social.

Un proyecto que busque la paz positiva deberá apostarle al fortalecimiento del pluralismo político y a una ampliación democrática que enriquezca el debate público sobre los amplios retos que afronta la sociedad colombiana. Como se mencionó, este hecho supone una serie de garantías en el escenario de apertura democrática, particularmente para movimientos y organizaciones sociales en los territorios más afectados por el conflicto, resaltando aquí la importancia de generar garantías de seguridad.

La entrada de nuevas voces y proyectos en el espectro político busca romper con el vínculo entre la política y las armas. En Colombia, la participación política de la oposición no puede analizarse de manera aislada al contexto social nacional, en el que se ha puesto en evidencia un sistema político que sustenta la violación sistemática de derechos humanos. Hay que tener presente que la oposición política es un derecho fundamental que va más allá de los partidos y movimientos políticos, pues se extiende a la ciudadanía que está facultada para participar en el control del poder político. Así, la oposición política no se limita al trabajo realizado en el Congreso de la República; su ejercicio, de acuerdo con Osorio, Nieto y Giraldo (2020), se produce en un marco más amplio determinado por las variables del contexto, entre ellas el sistema 
de partidos políticos, la igualdad social o la existencia del pluralismo cultural, religioso o político.

\subsection{Estatuto de la Oposición}

La oposición política en Colombia ha tenido una historia marcada por graves vulneraciones, donde prácticas como el bipartidismo del Frente Nacional derivaron en el surgimiento de las guerrillas marxistaleninistas y de otros movimientos de manera subsecuente, que han nacido como una respuesta a la cooptación de la libertad política de grupos y movimientos sociales con programas de gobierno distintos y apartados de la clase política tradicional del país. Un hito histórico que vale la pena recordar en este punto fue el exterminio de toda una colectividad política: la Unión Patriótica. Este hecho es el claro ejemplo de una democracia imperfecta, un genocidio que se inscribe en el proceso de exterminio de fuerzas políticas de oposición de manera sistemática.

Fue la Constitución Política de 1991 la que plantó los cimientos de un sistema incluyente y plural, que tuviera como máxima el respeto por las minorías y propendiera por la creación de garantías para el goce efectivo de derechos humanos por parte de la población que habita el territorio nacional. No obstante, es hasta la firma del Acuerdo de Paz que se advierte que el ejercicio de la política no se circunscribe solamente a la participación en el sistema político y electoral, ya que se deben abrir espacios de intervención real de todas y cada una de las organizaciones y movimientos sociales populares que pretendan ejercer algún tipo de oposición a las diferentes autoridades gubernamentales (Calderón, 2020). Este precedente, planteado como prelación en el punto 3.2.1.2.c del Acuerdo, tuvo como consecuencia que hoy en día en partidos y movimientos políticos exista un Estatuto de la Oposición. 
Con base en lo establecido en el Acto Legislativo 01 de 2016, relativo a los instrumentos jurídicos para el desarrollo normativo del Acuerdo Final, se expide la Ley 1909 de 2018, mediante la cual se adopta el Estatuto de la Oposición Política. Este es un hecho relevante por cuanto la historia del país, como se mencionó, ha tenido episodios de violencia que han sido alimentados por el ejercicio exacerbado del poder de unos pocos en detrimentos de las minorías políticas. Así, este es un avance fundamental para la participación política en el país. De acuerdo con la Procuraduría General de la Nación (2020), en el nivel nacional hay tres organizaciones políticas declaradas como independientes y cinco de oposición. En el orden territorial se realizaron 198 declaratorias departamentales y 5491 municipales, de las cuales 2981 son de Gobierno, 2146 de independientes y 562 de oposición.

\subsection{Mecanismos democráticos de participación ciudadana}

Este pilar tiene como principal propósito la materialización de componentes democráticos que contribuyan a una mayor participación de sectores sociales, garantizando una mayor incidencia política y poniendo en el debate público temas sensibles para la sociedad colombiana como lo son la movilización y la protesta. La importancia de este punto radica en que representa un cambio histórico en el cual las organizaciones y movimientos sociales rompen con el imaginario del Estado opresor, puesto que este pasa a ser un actor con el cual se puede negociar y con el que se puede plantear un aprendizaje mutuo en los distintos procesos organizativos y sociales. La fuerza de esta iniciativa rompe con el imaginario del Estado depositario de la fuerza y lo reubica en una posición de legitimidad que surge desde lo local.

Esta democratización de la participación ciudadana está intrínsecamente relacionada con la apuesta de las organizaciones y movimientos sociales por una mayor autonomía, especialmente en espacios institucionales donde en ocasiones esta se restringe al verse obligados a acogerse 
a la lógica y los límites establecidos por la institucionalidad: quiénes pueden participar, cómo, cuándo, dónde y para qué (Consejo Nacional de Participación Ciudadana, 2017). Según esto, la participación ciudadana ha ido tomando un nuevo rumbo en el cual, a través de vías no institucionales como la movilización social, se ven reflejadas las preferencias de las organizaciones debido a la autogestión de sus iniciativas sin la necesidad de ceñirse a un marco normativo propiciado por el mismo Estado.

Teniendo en cuenta estas ideas, en una democracia imperfecta se hace esencial una ley estatutaria que ofrezca garantías y promueva la participación. Sin embargo, como menciona Carlos Duarte (2021), se viene un año de elecciones y como se ha visto de manera evidente, la otrora brecha entre movimientos sociales y participación política electoral se ha venido cerrando de manera consistente. Salen a la luz temas sociales como la regularización de la movilización y la protesta, la cual es poco clara y bastante ambigua. En un Estado social de derecho como lo es Colombia en el papel, basta con ver historias como la de Dilan Cruz o Javier Ordóñez, o la muerte sistemática de líderes sociales, para darse cuenta de que las medidas que se han tomado hasta el momento en esta materia han fracasado.

En un mundo ideal de protestas pacíficas, donde existen garantías para que cualquier uso excesivo de la fuerza sea individualizado y judicializado, este tipo de normativas no tendrían la urgencia que hoy por hoy tiene la sociedad colombiana. El aprendizaje de las experiencias que ha tenido el Estado al abordar estas situaciones será primordial. Primero, es imperativo no caer en generalizaciones que alimenten el imaginario de "todo el que sale es vándalo" y, por el contrario, hacer un gran esfuerzo respecto a la confianza con los manifestantes pacíficos, que usualmente son la mayoría. 
En segundo lugar, la regulación de la protesta debe tener en cuenta la concertación y el diálogo con organizaciones civiles, con sindicatos y líderes que representan los intereses de los colectivos, y con la academia. También es importante tener una visión preventiva más que reactiva, realizando trabajos previos por parte de las autoridades, para que garanticen que no se infiltren otros actores que deslegitiman la acción política no violenta de la protesta.

El ejercicio de la participación y la organización social está afrontando enormes dificultades asociadas con amenazas, y un riesgo latente de líderes y lideresas sociales en su ejercicio de defensa de los derechos humanos, hecho que es altamente preocupante al no existir acciones y mecanismos expeditos que garanticen el derecho a la movilización y la protesta. En Colombia el diseño institucional dificulta la participación en política de los grupos sociales que no son afines a los intereses del régimen político de turno. No es extraño que las guerrillas de los años setenta y ochenta se inscribieran en un modelo de guerrilla de partido que cuestionara las estructuras de poder, insertando en la agenda nacional temas de gran relevancia como los derechos humanos, los valores democráticos o la paz.

Por otro lado, dentro de esta dinámica de apertura y participación de nuevos actores en la escena democrática, se resalta, como ya se mencionó, el recrudecimiento de la violencia en los territorios donde el Acuerdo de Paz ha sido tímido en su implementación. Según cifras de Indepaz (2020), entre el 2016 y el 2020 se registraron 1091 asesinatos, de los cuales 695 han ocurrido a lo largo del actual gobierno (figura 4).

En la figura 5 se pueden observar en detalle las regiones en las cuales se ha concentrado esta dinámica de asesinatos a líderes y defensores de derechos humanos después de la firma del Acuerdo de Paz. 


\section{Figura 4. Asesinato de líderes sociales 2016-2020}

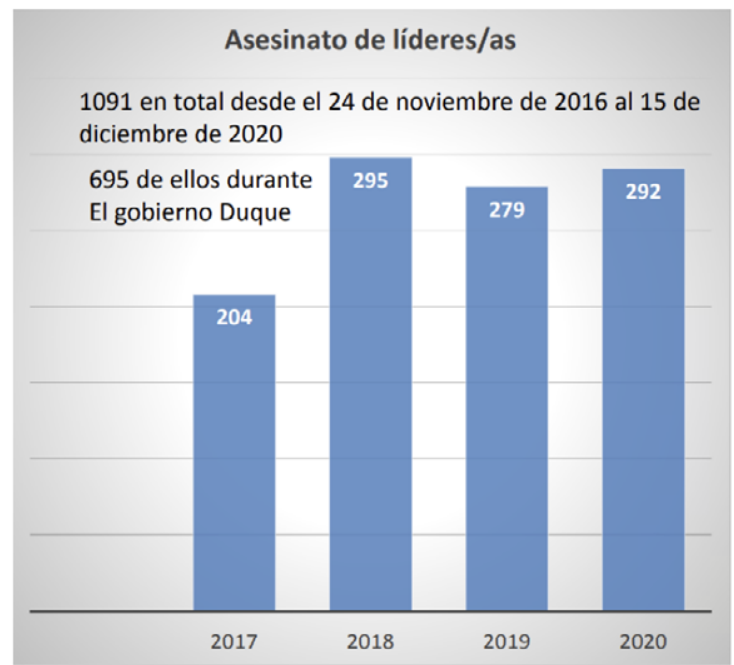

Fuente: Indepaz (2020).

Las figuras 4 y 5 permiten analizar que las zonas que han sido más afectadas por el conflicto armado, y sobre las cuales deberían existir acciones contundentes en la garantía de seguridad del territorio, afrontan graves vulneraciones en materia de derechos humanos. Las situaciones más críticas se presentan en el norte y suroccidente del Cauca, bajo Cauca y norte de Antioquia, Pacífico nariñense, Putumayo y Catatumbo. Además, son regiones que presentan dinámicas relacionadas con la recomposición de actores armados en disputa por el control territorial, rentas de narcotráfico, apropiación de tierras, entre otros factores que imposibilitan la llegada de la paz. Por esto, el llamado que hace la Procuraduría General de la Nación es fundamental para avanzar en el debate legislativo en torno a este proyecto de ley que contiene las garantías para la creación y fortalecimiento de las organizaciones y movimientos sociales. 
Figura 5. Regiones que concentran el asesinato a líderes sociales

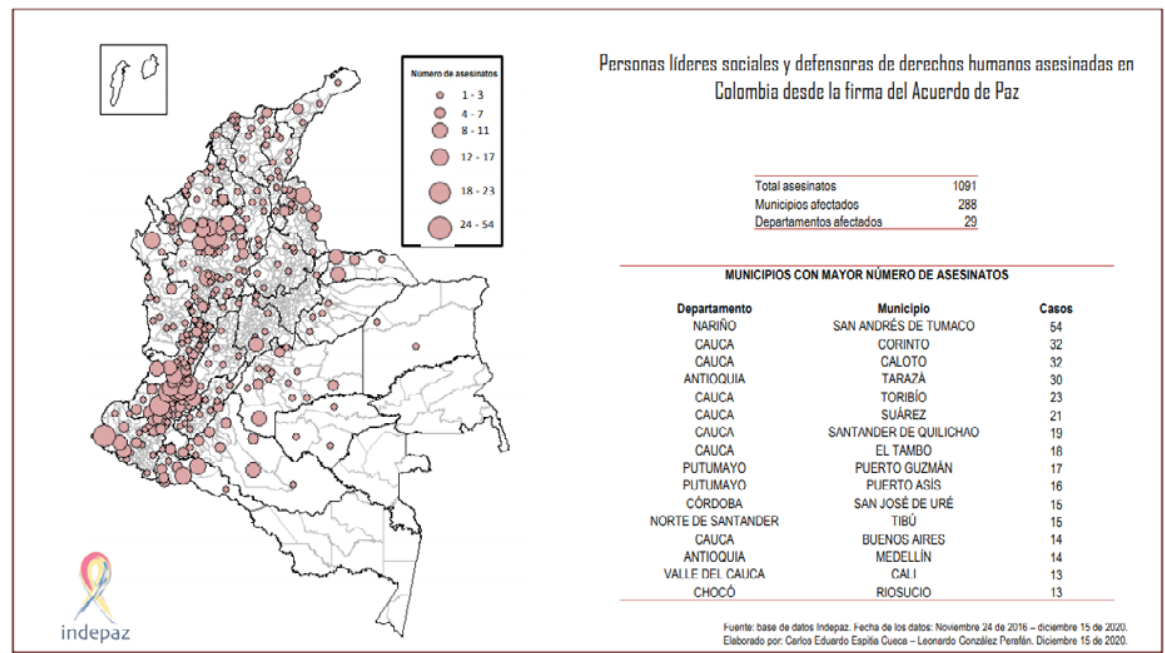

Fuente: Indepaz (2020).

\subsection{Medidas efectivas para promover la participación en la política nacional, regional y local}

Las medidas para promover la participación política en los distintos niveles territoriales (nacional, regional y local) parten del reconocimiento de la necesidad de una transformación de la cultura o forma de ejercer la democracia en el ámbito nacional, una mayor autonomía e independencia de la autoridad electoral y la promoción de un pluralismo político que impulse la participación política de los ciudadanos en las zonas más alejadas del país. El informe de la Procuraduría General de la Nación (2020) refleja avances en este aspecto, como: campañas en las que se tramitaron alrededor de 60000 cédulas en zonas afectadas por el conflicto armado; el impulso al Plan Ágora para minimizar los riesgos de corrupción electoral; la instalación de más mesas de votación para las elecciones de 2019; y la promoción de la representación política de poblaciones afectadas por 
el conflicto, en que está pendiente la reglamentación de las 16 curules en la Cámara de Representantes para las víctimas del conflicto armado, lo cual se pactó en el Acuerdo de Paz.

Para el caso de las comunidades rurales, son bajas las medidas que promueven una mayor participación e incidencia de estas en los procesos políticos. Por un lado, los partidos que representan los intereses de las comunidades étnicas enfrentan retos relacionados con la búsqueda de afinidad de sus programas políticos con otros sectores. Para el caso de las comunidades afrodescendientes, los principales retos se observan en la necesidad de cohesionar un proyecto político que represente al total, o al menos a la mayoría de las organizaciones afro, canalizando sus esfuerzos a través de la curul que tienen en la Cámara de Representantes.

En el caso de la población campesina, al no tener circunscripciones especiales como sí las tienen las comunidades étnicas, el panorama político y de representatividad se hace más adverso, aunque cabe resaltar la presencia en el Senado de dos congresistas con visiones cercanas a la realidad del campesinado. Aquí, como menciona Duarte (2021), las organizaciones de calado nacional como la Asociación Nacional de Usuarios Campesinos de Colombia (ANUC), la Asociación Nacional de Zonas de Reserva Campesina (ANZORC) y la Federación Nacional Sindical Unitaria Agropecuaria (FENSUAGRo) buscarán enfilar baterías para garantizar su participación en la vida electoral.

Estas reflexiones reiteran la necesidad de un proyecto de reforma política que ponga de relieve la autonomía, independencia y modernización del sistema electoral, además de la urgencia de promover un debate legislativo que conduzca a la aprobación de proyectos de ley que brinden garantías a las organizaciones y movimientos sociales. La participación política es fundamental en la construcción de la legitimidad del Estado, siendo este un paso necesario en la concurrencia de reformas estructurales que fortalezcan la democracia y que sean provechosas en los territorios. 


\section{Solución al problema de drogas ilícitas}

Una de las especificidades del Acuerdo es el papel central que tiene la política de sustitución conocida como Programa Nacional Integral de Sustitución de Cultivos Ilícitos (PNIS). Este programa, caracterizado desde sus inicios por una serie de incumplimientos en su implementación, ha venido alejándose de esa idea de promesa de cambio para los/as actores/as rurales. Un hito que marcó el desarrollo del programa podría relacionarse con el tránsito a una nueva administración que lo ve con recelo, que no ha asumido los problemas presupuestales, y que promueve acciones como la fumigación y la erradicación forzada. Esta situación se desarrolla en un contexto de riesgo para los liderazgos comunitarios, con fuertes opositores (legales e ilegales) en las escalas local y nacional, principalmente.

Este panorama desconoce las bondades de un programa que le apunta a la transformación productiva hacia economías legales y le abre las puertas a un mayor acceso a la tierra, a bienes públicos y a una mejor calidad de vida a los habitantes del territorio (Gutiérrez, Machuca y Cristancho, 2019). A su vez, la adecuada implementación del PNIS permitiría al Estado una mayor presencia territorial, además de la posibilidad, como muy pocas han existido, de desmontar las economías ilícitas que han alimentado las dinámicas de conflicto. Gutiérrez et al. (2019) resaltan la incapacidad del Estado, que se expresa en burocracias débiles con bajo margen de decisión; la descoordinación entre entidades y con el mismo Acuerdo; y una exclusión social que se manifiesta en procesos políticos y administrativos.

Se puede decir que los enfoques que ha tenido el PNIS se enmarcan en las pautas políticas que emanan de las administraciones de turno. Algunos analistas exponen que el periodo Santos se caracterizó por una alta concertación con las comunidades, pero una baja administración. Con el arribo de Duque al poder, se ha asumido una posición muy tímida respecto a cumplir algunos compromisos y se han establecido pocos acuerdos con las comunidades. Según la Oficina de Naciones Unidas 
contra la Droga y el Delito (2020), lo que sí se consolidó fue el número definitivo de población y los territorios que el Programa atenderá durante su vigencia: 99097 familias con una cobertura territorial que se delimitó a 56 municipios y 14 departamentos.

El giro que ha tenido la política antidrogas en Colombia puede explicarse a través de su replanteamiento como instrumento de paz y no de guerra. Esto quiere decir que las iniciativas en materia de cultivos de uso ilícito requieren de alianzas políticas en los distintos niveles (nacional, regional y local), pues se enfrentan a enclaves políticos y económicos, y a coaliciones sólidamente establecidas que las dejan al vaivén de esta política pública. Así, la coalición santista pro paz 2018 tuvo la capacidad de impulsar reformas significativas, como detener la aspersión aérea, aunque con límites en el desarrollo de medidas hacia la inclusión y el fortalecimiento del Estado (Gutiérrez et al., 2019). Esto llevó a un debilitamiento de la política pública y terminó por ceder ante el partido oficial de Gobierno, que tiene una agenda de retorno a la guerra contra las drogas.

\subsection{Evidencias de incumplimiento}

Los incumplimientos del Gobierno, de cara a los acuerdos con las comunidades en el marco del PNIS, se hacen sentir a través de las voces de muchos que se acogieron a este programa, con la esperanza de salir de las relaciones que giran en torno al cultivo de coca y las implicaciones de esto en los territorios. Bajo la promesa de "un territorio en paz", en departamentos como el Guaviare las comunidades campesinas de las veredas de municipios como El Retorno o San José del Guaviare muestran un inconformismo notorio por el cumplimiento parcial del PNIS. En palabras de una mujer campesina de la vereda Chaparral Medio, ubicada en el municipio de El Retorno: "Además de no pagar todos los compromisos, están desafiliando a las personas. Se está hablando en la zona de prepararse para un nuevo paro en protesta a este incumplimiento y de volver a sembrar coca en caso de no ser escuchados" (conversación personal, 29 de noviembre de 2020). 
En la vereda Caño Pava, ubicada en el mismo municipio, las comunidades manifiestan que se sumaron a los acuerdos de San José del Guaviare para erradicar el cultivo de coca, sin embargo, los campesinos y campesinas sienten esto como un engaño del Gobierno, que les hizo terminar los cultivos sin darles la contraparte establecida en el PNIS. Estas evidencias testimoniales de incumplimiento se enmarcan en la crítica situación de liderazgos involucrados en el programa, quienes afrontan las discusiones sobre una posible reanudación de la fumigación con glifosato. De acuerdo con información de la Coordinadora Nacional de Cultivadores de Coca, Amapola y Marihuana (CoccAM, 2018), la mayoría de los líderes asesinados participaban en las juntas de acción comunal de su vereda y coordinaban los comités cocaleros de sustitución.

Ahora bien, más allá de estas situaciones, se evidencia falta de voluntad política del Gobierno nacional para cumplir tanto los acuerdos individuales como colectivos suscritos en el marco del PNIS. Lo anterior se puede sustentar con base en la estrategia actual de erradicación forzada y la promoción de fumigaciones, dejando de lado la sustitución voluntaria de cultivos y el desarrollo de proyectos alternativos. Un hecho diciente que exponen Bulla Beltrán y Henao-Izquierdo (2021), es que en el 2019 no se hayan reportado nuevas vinculaciones al PNIS, lo cual significa que las 99097 familias fueron inscritas, casi que en su totalidad, durante el gobierno Santos. En contraste, el actual Gobierno desvinculó del programa a 1685 familias por supuestos incumplimientos, entre agosto y diciembre de 2019.

Otro hecho relevante es que la administración actual concibe al PNIS no como un programa de transformación del campo que se articula con la RRI, sino como una estrategia enfocada en reducir las hectáreas cultivadas de coca mediante la entrega de subsidios a cultivadores. El trasfondo de esto es la fractura de la integralidad de esta apuesta y la persistencia de cultivos de uso ilícito en entornos de pobreza y marginalidad. 
Asimismo, se encuentra la incapacidad y debilidad institucional por parte del Estado para atender el total de demandas, quejas y reclamos ${ }^{12}$. Para dimensionar esto, la desproporción entre funcionarios y personas por atender es muy alta. Según un estudio del Observatorio de Tierras (2019), es más o menos un funcionario por cada 710 usuarios. El resultado de esto es la imposibilidad de llevar a cabo una transformación territorial y un óptimo tránsito hacia las economías legales. La figura 6 refleja esta realidad.

\section{Figura 6. Relación funcionarios PNIS-usuarios}

\begin{tabular}{l|c|c|c|}
\hline \multicolumn{1}{c|}{ Departamento } & Nümero de funcionarios PNIS & $\begin{array}{c}\text { Múmero de familias inscritas PNIS- } \\
\text { Informe UNODC No. 17 }\end{array}$ & Relación inscritos;funcionarios \\
\hline Bogotá & 34 & & \\
Jurídicos & 15 & & 1308 \\
Antioquia & 9 & 496 & 165,3 \\
Arauca & 3 & 12951 & 2590,2 \\
Caquetá & 5 & 5685 & 947,5 \\
Cauca & 6 & & \\
Choć & 1 & 5996 & 1199,2 \\
Córdoba & 5 & 7251 & 1450,2 \\
Guaviare & 5 & 9702 & 1212,7 \\
Meta & 8 & 17235 & 1436,2 \\
Nariño & 12 & 3000 & 750 \\
Norte de Santander & 4 & 20331 & 1694,2 \\
Putumayo & 12 & 2754 & 550,8 \\
Sur de Bolivar & 5 & 1066 & 355,3 \\
Valle del Cauca & 3 & 826 & 275,3 \\
Vichada & 3 & & \\
Sistema de información & 3 & & \\
Supervisión & 6 & 99070 & \\
Total & 139 & & \\
\hline
\end{tabular}

Fuente: Observatorio de Tierras (2019).

12 Según datos de la Consejería, el PNIS cuenta con un total de 139 personas en el ámbito nacional, las cuales deben atender las demandas, quejas y reclamos de alrededor de 99000 familias inscritas (Gutiérrez, et al., 2019). 


\subsection{El caso de Tailandia}

A pesar de haber tenido una alta presencia de cultivos de uso ilícito desde la década de los sesenta, Tailandia es un país ejemplo en la disminución drástica de cultivos de amapola que se usaban para la producción de heroína. ¿Cómo ocurrió esto? Durante más de 30 años la intervención del Estado ha pasado por distintas etapas. Este es un proceso en el cual han concurrido actores que van desde la monarquía hasta las comunidades de orden local, incluyendo la activa participación del sector privado. Esta confluencia es la que ha nutrido el proyecto y lo ha hecho sustentable. En este acápite, vale la pena aclarar que los casos de Tailandia y Colombia son distintos y los contextos en los cuales se desarrollan las estrategias difícilmente son comparables, en gran medida por motivos políticos, sociales y aquellos vinculados al conflicto armado colombiano.

Mientras que en Tailandia las operaciones de erradicación de cultivos ilícitos fueron suspendidas, los programas de desarrollo alternativo, paralelamente, mostraban resultados. La experiencia colombiana nos muestra la difícil condición de erradicar cultivos ilícitos para iniciar proyectos productivos alternativos. Quizás la crítica al enfoque colombiano estaría encaminada a lo siguiente: para que las familias puedan acceder a las alternativas y oferta institucional, deben empezar por arrancar las plantas de coca, las cuales son el sustento de muchas familias de la ruralidad. Otra diferencia importante radica en cómo se proyecta la estrategia. En el caso de Tailandia, se buscó darle prioridad al bienestar socioeconómico de las comunidades, esto es, transformar las condiciones de vida de quienes dependían de esta actividad. En Colombia, como se mencionó anteriormente, se privilegia la estrategia de la disminución de cultivos de coca sembrados.

En cuanto a ecosistemas y recuperación de zonas ambientales, en Tailandia la política pública estuvo acompañada de la generación de compromisos para conservar el medio ambiente. De aquí surgieron iniciativas 
de reforestación y un ordenamiento territorial claro que definió las áreas de intervención y priorización del plan. El resultado de esto es que para 2016, la relación entre bosque y área cultivada fue de $77 \%$ y $8 \%$, respectivamente (Garzón, 2019). Para el caso de Colombia, sería importante que la sustitución de cultivos y el avance de proyectos productivos en las zonas priorizadas respondan al principio de sostenibilidad y de resiliencia (capacidad de reorganizarse) de los sistemas productivos.

Por último, la generación de cadenas de valor sostenibles y una promoción de la agroecología como alternativa productiva podrían impactar de manera positiva en la generación de ingresos de las comunidades, y permitiría superar las brechas socioeconómicas, abriendo la posibilidad de conectar los mundos rural-urbano en una relación simbiótica que beneficie las cadenas productivas y evite intermediaros en los procesos. El caso tailandés refleja en parte esto, ya que buscó generar cadenas de valor que se conectaran a los mercados. En Colombia existen iniciativas que van encaminadas a lo mismo, aunque el papel de los intermediarios y la desarticulación de los mercados siguen siendo un obstáculo para el desarrollo de proyectos productivos alternativos.

El caso de Tailandia es un referente en la notable disminución de cultivos ilícitos a través del impulso de un marco jurídico sólido, acompañado de cambios sociales que privilegiaron el bienestar de las comunidades en la necesaria articulación con los componentes económico y productivo. Su experiencia puede ser un espejo para el caso colombiano, además de arrojar luces que la acerquen al camino que tiene que transitar el país para la implementación de una estrategia ajustada a nuestras realidades territoriales.

\section{Conclusiones y recomendaciones}

A lo largo del texto se resalta la importancia de despertar y encauzar emociones que movilicen el proceso de construcción de la paz anhelada. En este sentido, las emociones, como una idea marco, son transversales 
a todo lo que mueve al ser humano. Estas son, en palabras de García (2020), lo primero y lo esencial, aquello sin lo cual la vida animal es irreconocible. La cultura, la ciencia, la filosofía, la justicia, las religiones, entre muchas otras realidades humanas, obedecen a la valoración positiva de una chispa emocional que le dio origen. Ahora, promover un proyecto de paz que transforme las emociones heredadas de nuestra historia y de aquellos afectos anclados en nuestra sociedad, no es una tarea que pueda lograrse en el corto y mediano plazo. Pareciera que estamos ante un modelo de paz imperfecta, en el cual existen intenciones y acciones que buscan la paz, con sus aciertos y tropiezos.

En este punto cabe preguntarse si el modelo de paz al que aspiramos en Colombia debería oscilar entre la paz negativa y la positiva, ya que plantear una paz absoluta podría incluso redundar en lo utópico o lo ideal. Quizás, debido a nuestro contexto rural, sea más prudente tener un concepto de paz más amplio, que esté caracterizado por lo variable: regulación, transformación o resolución cotidiana de los problemas y de los conflictos creados por los propios humanos para sí, entre ellos o en su relación con la naturaleza (Harto, 2016). En este sentido, habiendo reconocido las posibles limitaciones para alcanzar un ideal de paz, se pueden plantear una serie de recomendaciones y propuestas de cara a la realidad fáctica.

La paz imperfecta pretende abordar este concepto de paz desde una realidad más dinámica e inacabada, reconociendo que las sociedades se encuentran en constantes procesos de transformación, pero que al mismo tiempo persiguen un estado de paz de acuerdo con las condiciones reales de los contextos sociales. Las siguientes recomendaciones se plantean en orden a gestionar las controversias e inconvenientes de una sociedad en etapa de posacuerdo, que aún convive con conflictos y con manifestaciones de violencia en sus distintas dimensiones. Así, vale la pena reflexionar en torno al ser humano como un ser dual, que por un lado puede ser conflictivo, pero por otro puede responder a los principios de la cooperación y el altruismo. 
Para el caso de la RRI, las recomendaciones apuntan al cierre de brechas socioeconómicas entre la Colombia rural y la urbana, garantizando un enfoque étnico y de género, así:

- Fortalecer e impulsar la activa participación de los actores rurales, lo cual generará un mayor sentido de pertenencia de las comunidades y una mayor legitimidad en los procesos que adelanta el Gobierno nacional, junto con más organizaciones civiles en las regiones más afectadas por el conflicto. En materia de género es importante que desde la Instancia Especial de Mujeres para el Enfoque de Género en la Paz se realice una transversalización de todos los indicadores incluidos en el Acuerdo, además de fortalecer la participación y vinculación de mujeres en la ruta PDET.

- Modernizar el catastro como tarea necesaria para mejores procesos de toma de decisiones. Además, la actualización de la base catastral del país permitirá una mejor y mayor identificación de predios susceptibles de ser adjudicados y aumentará la renta de los municipios.

- Aunar esfuerzos interinstitucionales para garantizar que los programas que promueven el acceso equitativo a la tierra cuenten con mayores fuentes de financiación y se fortalezcan las instancias regionales y locales.

- Gestionar las conflictividades territoriales que deberán dialogar con lo dispuesto en el artículo 55 del Decreto Ley 902 de 2017, buscando la construcción de una hoja de ruta concertada con las comunidades rurales, para la atención integral a estas situaciones. Será necesaria una estrategia acertada de cara a la interculturalidad.

- Fortalecer el enfoque territorial a través de iniciativas como los Consejos Territoriales de Paz, los cuales son liderados por las autoridades locales y pueden concebirse como espacios de reconciliación y construcción de paz. 
- Mayor articulación de los PDET con otros programas y apuestas de la RRI, ya que no deben limitarse a los PATR.

Para el punto de participación política, el trabajo mancomunado de distintos actores será crucial para la apertura democrática y la garantía de respeto a los derechos humanos en los territorios. Las recomendaciones son:

- Promover un pluralismo político que enriquezca el debate público sobre los amplios retos que afronta la sociedad colombiana. Para esto, el Acuerdo creó instancias que abren el camino a una política más deliberativa, en la cual se deberá impulsar la activa participación de la sociedad civil y su mayor incidencia en el sistema político-administrativo.

- Garantizar el buen funcionamiento de los Consejos Territoriales llevará a construir una agenda de diálogo continuo con las comunidades y, en general, con la sociedad civil, logrando canalizar las exigencias y demandas sociales, y entablar acuerdos que perduren, a pesar del trasegar político.

- Reglamentar la protesta social en Colombia, garantizando no solo la seguridad, sino también los compromisos de no repetición frente a los hechos de abuso de la fuerza pública. Esto se conecta con la necesidad imperativa de garantizar la seguridad de la integridad física y psicológica de los líderes y lideresas sociales en los territorios, sobre todo en aquellas zonas donde la violencia está resurgiendo.

Por último, las recomendaciones para la solución al problema de drogas ilícitas son de carácter estructural. Estas son:

- Cumplir con los compromisos que el Gobierno pactó con las comunidades rurales, garantizando, al menos, mínimos de subsistencia y promoviendo el desarrollo de proyectos productivos alternativos que generen ingresos en las zonas rurales. 
- El discurso de la lucha contra las drogas debe apuntar al abandono de la guerra contrainsurgente, además de una postura definitiva que frene el retorno a las aspersiones aéreas. Aquí deberá existir un alineamiento de las agencias del Gobierno para avanzar en una agenda de desarrollo rural con las comunidades.

- La sustitución voluntaria podría producir efectos positivos que apacigüen a Estados Unidos en relación con las hectáreas cultivadas y atienda las reivindicaciones de las comunidades rurales, particularmente las campesinas.

- El giro hacia economías lícitas deberá superar barreras de desfinanciación, en que será importante contar con voluntad política y una consecuente garantía de seguridad para líderes y lideresas que trabajan por un proyecto de paz, que en muchas regiones es aún tímido.

- Examinar cómo la coyuntura internacional permite una revisión de la lucha contra las drogas y un giro al desarrollo de estrategias centradas en la sustitución de cultivos de uso ilícito como las que plantea el PNIS.

Estas recomendaciones pretenden aportar al ejercicio reflexivo sobre un modelo de paz que suprima la violencia directa y además reduzca la violencia estructural. De esta manera, el proyecto de paz al que aspiramos no debe ser ajeno a las dinámicas de violencia territorial, más bien debe apuntar a la transformación de estas. La paz en Colombia se enmarca en un concepto que concibe la paz en sí misma como imperfecta, siempre inacabada y en constante transformación. No hay que olvidar que los conflictos son inherentes a las relaciones humanas. Promover consensos entre la diversidad es un reto que deberá entrelazar las agendas y buscar el diálogo asertivo entre el Estado y la sociedad civil. 


\section{Referencias}

Agencia Nacional de Tierras. Observatorio de Tierras Rurales. (2020). Acceso a tierras y adjudicación de baldios. Recuperado de https://otr.agenciadetierras.gov.co/OTR/Observatorio/AccesoATierras

Ahumada, Consuelo. (2020). La implementación del Acuerdo de paz en Colombia: entre la "paz territorial" y la disputa por el territorio. Problemas del Desarrollo. Revista Latinoamericana de Economía, 51(200), 25-47.

Alzate, Daniel. (2020). Concentración de la tierra y las Zonas de Interés de Desarrollo Rural, Económico y Social (Zidres) en los Montes de María, María la Baja y Carmen de Bolívar. Prolegómenos, 23(46), 51-70.

Arbeláez, Natalia. (25 de octubre de 2020). La paradoja de Santos: negociar un acuerdo transformador y no jugársela por ponerlo en marcha. Recuperado de https://lasillavacia.com/historias/historia-academica/la-paradoja-de-santosnegociar-un-acuerdo-transformador-y-no-jugarsela-por-ponerlo-en-marcha/

Aunta, Andrés y Barrera, Víctor. (2016). Conflictividades y agendas territoriales. Bogotá: Red Nacional de Programas regionales de Desarrollo y Paz/Centro de Investigación y Educación Popular. Recuperado de https://www.cinep.org. co/publicaciones/PDFS/20160702.conflictividades_agendas_territoriales.pdf

Bulla Beltrán, Diego y Henao-Izquierdo, Laura. (2021). La muerte lenta del PNIS en el Gobierno Duque. Revista 100 Días, (101).

Cabana, María. (2017). De los mecanismos alternativos de solución de conflictos en Colombia: acerca de su alcance y desarrollo para su implementación en los municipios de postconflicto. Recuperado de https://repository.ucatolica.edu.co/handle/10983/14606

Calderón, Julio. (2020). Estatuto de la oposición política colombiana. Antecedentes, retos, alcances y deudas del legislador colombiano. Recuperado de https://bdigital.uexternado.edu.co/handle/001/2683

Centro de Investigación y Educación Popular/Programa por la Paz [CinEP/PpP]. (2016). Movilización por la paz en Colombia: una infraestructura social clave para el posacuerdo. Bogotá: Centro de Investigación y Educación Popular. 
Contreras, Patricio y Montecinos, Egon. (2019). Democracia y participación ciudadana: tipología y mecanismos para la implementación. Revista de Ciencias Sociales, 25(2), 178-191. Recuperado de https://dialnet.unirioja. es/servlet/articulo?codigo $=7026001$

Consejo Nacional de Participación Ciudadana. (Abril de 2017). Documento de lineamientos para una ley estatutaria de garantías para la participación de organizaciones y movimientos sociales y para la movilización y la protesta social. Recuperado de http://participando.co/media/docs/leyes/Documento_lineamientos_Final.pdf

Coordinadora Nacional de Cultivadores de Coca, Amapola y Marihuana [COCCAM]. (10 de diciembre de 2018). Informe Nacional sobre la violación de derechos humanos en la implementación del punto 4 "Solución al Problema de Drogas Ilícitas" a la COCCAM. Recuperado de

Departamento Administrativo Nacional de Estadística [DANE] . (2014). Censo Nacional Agropecuario 2014. Recuperado de https://www.dane.gov.co/index. $\mathrm{php} /$ estadisticas-por-tema/agropecuario/censo-nacional-agropecuario2014\#: :text = De \% 20acuerdo \% 20con \% 20el \% 20bolet \% C3 \% ADn,y \% 20 $264 \% 20 \mathrm{mil} \% 20$ son $\% 20$ mujeres

Departamento Administrativo Nacional de Estadística. (2018). Censo Nacional de Población y Vivienda. Recuperado de https://www.dane. gov.co/index.php/estadisticas-por-tema/demografia-y-poblacion/ censo-nacional-de-poblacion-y-vivenda-2018

Departamento Nacional de Planeación. (2015). El campo colombiano: un camino hacia el bienestar y la paz, Misión para la Transformación del Campo. Recuperado de https://www.dnp.gov.co/programas/agricultura/Paginas/ Informe-misi \% C3\%B3n-FInal.aspx

Duarte, Carlos. (6 de febrero de 2021). 8 spoilers de la cuestión étnico-campesina en 2021. Recuperado de https://lasillavacia.com/historias/ historias-silla-llena/8-spoilers-de-la-cuestion-etnico-campesina-en-2021/

El Espectador. (24 de abril de 2020). Las críticas al Gobierno por "simular" la implementación de los PDET. Recuperado de https://www.elespectador. com/colombia2020/pais/las-criticas-al-gobierno-por-simular-la-implementacion-de-los-pdet-articulo-915921/ 
Fisas, Vicenç. (2006). Cultura de paz y gestión de conflictos. Barcelona: Icaria.

Galtung, Johan. (2003). Paz por medios pacíficos. Paz y conflicto, desarrollo y civilización. Bilbao: Bakeaz.

García, Mauricio. (2020). El país de las emociones tristes. Bogotá D.C.: Editorial Ariel.

Garzón, Juan Carlos. (29 de enero de 2019). Tailandia fue declarada libre de cultivos ilícitos ¿Qué puede aprender Colombia? Recuperado de https:// lasillavacia.com/historias/historias-silla-llena/tailandia-fue-declaradalibre-de-cultivos-ilicitos-que-puede-aprender-colombia-/Gobierno de Colombia. (2018). Plan Marco de Implementación Acuerdo final para la terminación del conflicto y la construcción de una paz estable y duradera. Recuperado de https://colaboracion.dnp.gov.co/CDT/Conpes/ Econ \% C3 \% B3micos /3932_Anexo \% 20B_Plan \% 20Marco \% 20de \% 20 Implementaci \% C3 \% B3n \% 20(PMI).pdf

Gobierno Nacional y FARC-EP. (2016). Acuerdo final para la terminación del conflicto y la construcción de una paz estable y duradera. Recuperado de https://www.jep.gov.co/Documents/Acuerdo \% 20Final/Acuerdo \% 20 Final\%20Firmado.pdf

Gutiérrez, Francisco; Machuca, Diana y Cristancho, Sebastián. (2019). ¿Obsolescencia programada? La implementación de la sustitución y sus inconsistencias. Análisis Político, 32(97), 136-160.

Harto, Fernando. (2016). La construcción del concepto de paz: paz negativa, paz positiva y paz imperfecta. Cuadernos de Estrategia, (183), 119-146.

Hoffmann, Odile. (2001). Conflictos territoriales y territorialidad negra. El caso de las comunidades afrocolombianas. Recuperado de https://halshs.archives-ouvertes.fr/halshs-00463449/document

Instituto de Estudios para el Desarrollo y la Paz [INDEPAZ]. (21 de diciembre de 2020). Posacuerdo traumático: coletazos en la transición desde el Acuerdo de Paz al posconflcito. Recuperado de http://www.indepaz.org.co/informe-de-indepaz-posacuerdo-traumatico-coletazos-en-la-transicion-desdeel-acuerdo-de-paz-al-posconflicto/ 
Instituto Geográfico Agustín Codazzi [IGAc]. (2015). Tan solo el 0,3 por ciento de todo el territorio colombiano corresponde a áreas urbanas: IGAC. Recuperado de https://igac.gov.co/es/noticias/tan-solo-el-03-por-ciento-detodo-el-territorio-colombiano-corresponde-areas-urbanas-igac

Kroc Institute for International Peace Studies. (noviembre de 2019). Tres años después de la firma del Acuerdo de Paz en Colombia: hacia la transformación territorial. Recuperado de http://peaceaccords.nd.edu/wp-content/uploads/2020/06/Cuarto-Informe-Final-with-Annex-Link.pdf

Kroc Institute for International Peace Studies. (mayo de 2021). El Acuerdo Final de Colombia en tiempos del COVID-19: apropiación institucional y ciudadanía como clave de la implementación. Recuperado de https://keough.nd.edu/ publications/el-acuerdo-final-de-colombia-en-tiempos-del-covid-19-apropiacion-institucional-y-ciudadana-como-clave-de-la-implementacion/

Llorente, María Victoria. (25 de septiembre de 2020). La paz posible: una visión más realista de cómo alcanzar la paz. Recuperado de http://www. ideaspaz.org/publications/posts/1902

Noticias Caracol. (21 de febrero de 2021). Robo, usurpación y despojo: la guerra sin cuartel que se libra en Colombia por la tierra. Recuperado de https:// noticias.caracoltv.com/colombia/robo-usurpacion-y-despojo-la-guerrasin-cuartel-que-se-libra-en-colombia-por-la-tierra

Nussbaum, Martha. (2017). Emociones politicas: ¿por qué el amor es importante para la justicia? Barcelona. Paidós.

Observatorio de Tierras Rurales. (2019). Acceso a tierras y adjudicación de baldíos. Recuperado de https://otr.agenciadetierras.gov.co/OTR/ Observatorio/AccesoATierras

Oficina de Naciones Unidas contra la Droga y el Delito. (31 de diciembre de 2020). Informe No. 23. Programa Nacional Integral de Sustitución de Cultivos Ilícitos. Recuperado de https://www.unodc.org/colombia/es/43-711-hectareas-de-cultivos-ilicitos-erradicadas-de-forma-voluntaria_-nuevo-informe-pnis.html

Osorio, Julialba; Nieto, Libia; Giraldo, Reinaldo. (2020). Participación política de la oposición en Colombia después del Acuerdo de Paz de 2016. Entramado 16 (2), 252-262. Recuperado de https://revistas.unilibre.edu.co/ index.php/entramado/article/view/6695/5988 
Presidencia de la República. (24 de agosto de 2016). Documento de notas explicativas sobre los 6 puntos del Acuerdo Final para la Terminación del Conflicto y la Construcción de una Paz Estable y Duradera. Bogotá. Recuperado de http://es.presidencia.gov.co/noticia/160824-Documento-de-notas-explicativas-sobre-los-6-puntos-del-Acuerdo-Final-para-la-Terminacion-del-Conflicto-y-la-Construcci \% C3 \% B3n-de-una-Paz-Estable-y-Duradera

Presidencia de la República. Decreto 902 de 2017. Por el cual se adoptan las medidas para facilitar la implementación de la Reforma Rural Integral contemplada en el Acuerdo Final en materia de tierras, específicamente en el procedimiento para el acceso y formalización del Fondo de Tierras. Mayo 29 de 2017. Recuperado de https://www.minagricultura.gov.co/Normatividad/Decretos/Decreto \% 20Ley \% 20No. \% 20902\%20de\% 202017.pdf

Procuraduría General de la Nación [PGN]. (2020). Segundo informe al Congreso sobre el estado de avance de la implementación del Acuerdo de Paz/20192020. Recuperado de https://www.procuraduria.gov.co/portal/Paz.page

Procuraduría General de la Nación. (7 de enero de 2021). Informe sobre el estado de avance de la implementación de las estrategias de acceso a tierras y uso del suelo rural contempladas en el Acuerdo de Paz. Recuperado de https:// www.procuraduria.gov.co/portal/media/file/Informe \%20sobre $\% 20$ Acceso \% 20y \%20Uso \% 20de\%20la \%20Tierra \%20Def \%2007_01_2021.pdf

Reuters. (2021). ONU pide a Colombia cumplir el acuerdo de paz con FARC y acciones para detener violencia. Recuperado de https://www.reuters.com/ article/colombia-onu-idLTAKBN2AN1XZ

Román López, María Teresa. (2006). El concepto de ahimsa en el hinduismo, el budismo y el jainismo. Cuadernos del Marqués de San Adrián. Recuperado de https://qinnova.uned.es/archivos_publicos/qweb_paginas/4469/ revista4articulo8.pdf

Nelson Camilo. (2017). Estrategias para una reforma rural transicional. Bogotá: Centro de Estudios de Derecho, Justicia y Sociedad.

Sassen, Saskia. (2007). Una sociología de la globalización. Buenos Aires: Katz Editores.

Secretaría Técnica del Componente Internacional de Verificación CinEP/PPPCERAC. (Junio de 2019). Tercer informe de verificación de la implementa- 
ción del Enfoque de Género en el Acuerdo Final de Paz en Colombia para los Verificadores Internacionales Felipe González y José Mujica (A.F. 6.3.2). Recuperado de file:///C:/Users/felip/Downloads/Tercer-Informe-deImplementaci \% C3 \% B3n-del-Enfoque-de-G\% C3 \% A9nero-STCVI\%20(3).pdf

Secretaría Técnica del Componente Internacional de Verificación CinEP/PPP-CERAC. (Septiembre de 2020). Séptimo informe de verificación de la implementación del Acuerdo Final de Paz en Colombia. Recuperado de https://www. cinep.org.co/Home2/component/k2/828-septimo-informe-de-verificacionde-la-implementacion-del-acuerdo-final-de-paz-en-colombia.html

Secretaría Técnica del Componente Internacional de Verificación CinEP/PPP-CERAC. (Febrero de 2021). Octavo informe de verificación de la implementación del Acuerdo Final de Paz en Colombia. Recuperado de https://www. cinep.org.co/Home2/component/k2/864-octavo-informe-de-verificacionde-la-implementacion-del-acuerdo-final-de-paz-en-colombia.html

Stephenson, Carolyn. (1999). Peace Studies, Overview. In Lester Kurtz (Ed.), Encyclopedia of Violence, Peace and Conflic (Vol. 2). San Diego: Academic Press.

Vásquez, Katalina. (Noviembre de 2020). "LOS PDET han sido una frustración": el reclamo de las organizaciones a cuatro años del Acuerdo de Paz. Recuperado de https://www.cinep.org.co/Home2/component/k2/848-los-pdethan-sido-una-frustracion-el-reclamo-de-las-organizaciones-a-cuatro-anosdel-acuerdo-de-paz.html

Zuleta, Estanislao. (2015). Sobre la guerra. Revista Universidad de Antioquia, (319), 24-25. Recuperado de https://revistas.udea.edu.co/index.php/ revistaudea/article/view/22402 